Please do not remove this page

RMIT

UNIVERSITY

\title{
The contribution of constitutional supercooling to nucleation and grain formation
}

St John, D; Prasad, A; Easton, Mark; Qian, Ma

https://researchrepository.rmit.edu.au/esploro/outputs/9921862752501341/filesAndLinks?institution=61RMIT_INST\&index=null

St John, D., Prasad, A., Easton, M., \& Qian, M. (2015). The contribution of constitutional supercooling to nucleation and grain formation. Metallurgical and Materials Transactions A, 46A(11), 4868-4885.

https://doi.org/10.1007/s11661-015-2960-y

Document Version: Accepted Manuscript

Published Version: https://doi.org/10.1007/s11661-015-2960-y

Repository homepage: https://researchrepository.rmit.edu.au

(C) The Minerals, Metals and Materials Society and ASM International 2015

Downloaded On 2023/04/26 23:26:48 +1000 
Thank you for downloading this document from the RMIT Research Repository.

The RMIT Research Repository is an open access database showcasing the research outputs of RMIT University researchers.

RMIT Research Repository: http://researchbank.rmit.edu.au/

\section{Citation: \\ St John, D, Prasad, A, Easton, M and Qian, M 2015, 'The contribution of constitutional supercooling to nucleation and grain formation', Metallurgical and Materials Transactions A, vol. 46A, no. 11, pp. 4868-4885.}

See this record in the RMIT Research Repository at:

https://researchbank.rmit.edu.au/view/rmit:32759

Version: Accepted Manuscript

\section{Copyright Statement:}

(C) The Minerals, Metals and Materials Society and ASM International 2015

Link to Published Version:

http://dx.doi.org/10.1007/s11661-015-2960-y 


\title{
The Contribution of Constitutional Supercooling to Nucleation and Grain Formation
}

\author{
D.H. StJohn ${ }^{1 \mathrm{a}}$, A. Prasad ${ }^{1 \mathrm{~b}}$, M.A. Easton ${ }^{2 \mathrm{c}}$ and M. Qian ${ }^{2 \mathrm{~d}}$ \\ ${ }^{1}$ Centre for Advanced Materials Processing and Manufacturing (AMPAM), School of Mechanical and \\ Mining Engineering, The University of Queensland, St Lucia, QLD, Australia, 4072 \\ ${ }^{2}$ RMIT University, School of Aerospace, Mechanical and Manufacturing Engineering, GPO Box 2476, \\ Melbourne, VIC 3001, Australia

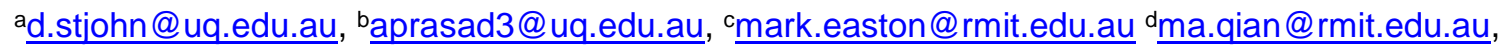

\begin{abstract}
The concept of constitutional supercooling (CS) including the term itself was first described and discussed qualitatively by Rutter and Chalmers (1953) in order to understand the formation of cellular structures during the solidification of tin, and then quantified by Tiller, Jackson, Rutter, and Chalmers (1953). On that basis, Winegard and Chalmers (1954) further considered 'supercooling and dendritic freezing of alloys' where they described how CS promotes the heterogeneous nucleation of new crystals and the formation of an equiaxed zone. Since then the importance of CS in promoting the formation of equiaxed microstructures in both grain refined and unrefined alloys has been clearly revealed and quantified. This paper describes our current understanding of the role of CS in promoting nucleation and grain formation. It also highlights that CS, on the one hand, develops a nucleation-free zone surrounding each nucleated and growing grain and, on the other hand, protects this grain from readily remelting when temperature fluctuations occur due to convection. Further, due to the importance of the diffusion field that generates CS recent analytical models are evaluated and compared with a numerical model. A comprehensive description of the mechanisms affecting nucleation and grain formation and the prediction of grain size is presented with reference to the influence of the casting conditions applied during the practical casting of an alloy.
\end{abstract}

\section{INTRODUCTION}

It is recognised that Constitutional Supercooling (CS) plays a significant role in enabling the formation, and refining, of equiaxed grain structures ${ }^{1,2}$. Successful nucleation depends not only on the generation of sufficient undercooling but also on the potency and distribution of heterogeneous nucleant particles and the thermal conditions within a casting during solidification. The focus of this paper is on the role that CS plays within the context of the total nucleation environment. The importance of solute has been known for a long time and in 1949 Cibula $^{3}$, building on previous research ${ }^{4-6}$, stated that there are 'concentration gradients in the liquid around solidifying dendrites, which retarded crystal growth and the release of heat of fusion and thus allowed the interior of the casting to undercool and new crystallites to form'. In fact, it has been shown that even for grain refinement by high intensity 
ultrasonication, the presence of an adequate amount of solute has proved to be essential in order to produce desired grain refinement ${ }^{7}$. This paper first briefly reviews the development of the concept of CS and the parameters $P$ and $Q$ that developed out of the CS model. Then we will focus on casting conditions where CS-induced grain refinement is the dominant refining mechanism in the bulk of a solidifying melt. It will be shown that CS promotes nucleation and grain formation through interaction between the developing CS and the heterogeneous particles responsible for triggering the nucleation events. This approach is a significant conceptual shift from the assumption that nucleation of grains occurs first followed by the growth of grains to the recognition that in the case of CS-driven nucleation, grain growth comes before nucleation except for the first nucleation events ${ }^{8,9}$. Therefore, nucleation is a continually repeating process of growth-nucleation-growth in a casting. On the other hand, CS creates a Nucleation-Free Zone (NFZ) around each growing grain as well as the eventual decrease in the amount of CS due to overlapping diffusion fields between adjacent growing grains ${ }^{10,11}$. However, CS also protects grains from melting due to thermal or compositional convection currents moving between and in front of the growing grains. Each of these mechanisms will be described to create a full picture of the role of CS in promoting nucleation and grain formation.

\section{CONSTITUTIONAL SUPERCOOLING AND THE SUPERCOOLING PARAMETERS $P$ AND $Q$}

It appears that the phenomenon of CS was first discussed by Ivantzov ${ }^{12}$. In his paper entitled "Diffusional undercooling during crystallisation of a binary alloy", Ivantzov formulated a description of the solute concentration in the liquid ahead of the solid-liquid (S-L) interface with the assumptions that the molten metal is not moving, the densities of the solid and liquid phases are the same and the release of latent heat is neglected. Ivantzov concluded that "During crystallisation/solidification of a binary alloy, which takes place by the heat transfer via a solid phase, a layer of undercooled melt is formed near the front (solid/liquid interface) even if the melt is superheated and the conditions corresponding to the equilibrium phase diagram exist at the interface between phases." Ivantzov further pointed out that this undercooling should be called diffusional undercooling, as it occurs because of the diffusional process taking place in the layer of the melt neighbouring the crystallisation/solidification front. However, Ivantzov did not discuss the effect of temperature gradient in this pioneering work.

The basic concept of CS was more rigorously formulated by Rutter and Chalmers ${ }^{13}$. They showed that "Segregation of impurities is shown to occur during solidification in a manner intimately related to the structure" for both tin and lead through well designed experiments and characterisation (the segregation of impurity was determined using a radioactive tracer technique with antimony 124). A theory, termed CS, was then developed by Rutter and Chalmers to account for the solidification structures induced by the segregation of impurities. The critical temperature gradient was also determined. Figure 1 summarises the CS theory of Rutter and Chalmers ${ }^{13}$. This was followed by the development of a quantitative description of the theory by Tiller, Jackson, Rutter, and Chalmers ${ }^{14}$. 
Winegard and Chalmers were the first to correlate CS and equiaxed grain formation during solidification ${ }^{15}$, and in particular they proposed the CS-driven nucleation hypothesis as illustrated in Figure $2^{15}$.

The basic mathematical formulations ${ }^{14,16}$ describing the distribution of solute in front of a growing interface were developed and compared with the breakdown of growth of a planar interface. Whilst the role of CS on the S-L interface stability and the formation of cellular dendritic structures were extensively considered in the literature ${ }^{14,17}$, as was the importance of heterogeneous nucleation on grain refinement ${ }^{3,18-25}$, much less consideration was given to the effect of solute on grain refinement. However, there were still some publications during this time that recognized the role of solute on grain refinement ${ }^{26}$. Enlightened by the criterion for $\mathrm{CS}^{14}$ advances in quantifying the role of solute began in the 1970's with Tarshis et al ${ }^{27}$ who found that in a range of $\mathrm{Ni}$ - and Al-based alloys the addition of solute led to substantial grain refinement. In addition, for the first time, they correlated the grain size with the Supercooling Parameter $P$, defined below, for both binary Ni-X alloy and Al-X alloys.

$P=\frac{m c_{0}(k-1)}{k}$

where $\mathrm{k}$ is the partition coefficient $\left(\mathrm{C}_{\mathrm{s}} / \mathrm{C}_{1}\right), m$ is the gradient of the liquidus and $C_{o}$ the alloy composition. The grain size showed a similar and convincing dependency on the parameter $P$ for both Ni-X alloy and Al-X alloys. This was the original parameter used to relate the effect of solute content on grain size with some success ${ }^{28-30}$.

There have been a number of approaches that have assisted, directly or inadvertently, in understanding the role of solute, and consequently CS, on grain refinement since Tarshis et al 27. One stream of thought has been to primarily associate the effect of CS on grain size with the growth restriction of dendrites ${ }^{28}$. A number of researchers observed that the rate of grain growth reduced with an increase in the solute content ${ }^{29-35}$. The rationale is that a slower growth rate leads to a later start and slower rate of recalescence which allows more time for nucleation to develop. The models of Maxwell \& Hellawell ${ }^{28}$ and Greer et al ${ }^{36-41}$ followed this path and they developed comprehensive models of grain refinement generally assuming a more or less isothermal melt.

Another approach has been to consider the importance of CS in developing a nucleation zone in front of the growing grains to facilitate further nucleation $9,10,42,43$. Whilst these models assumed a more or less isothermal melt for simplicity, this approach in essence considers a melt in which there is a thermal gradient, even if it is slight, and a wave of nucleation events occurring towards the thermal centre of the casting.

Experimental studies have produced a large amount of data relating grain size with various solute based parameters $27,30,32-34,44-53$. It is fortunate that what is a complex relationship between grain size and alloy composition ${ }^{36,38,54}$ can be in the first instance related to some simple parameters. Apart from the parameter $P$, the Growth Restriction Factor (GRF) or $Q$ is another such parameter, defined as 
$Q=m c_{0}(k-1)$

Note that $P=Q / k$. The relationship between grain size and $Q$ initially appeared as the growth rate of a grain was derived to be inversely proportional to $Q^{29,31,55,56}$ hence the term growth restriction factor was introduced ${ }^{30}$. Later the growth restriction factor was referred to as $Q^{41}$ and this is now recognised as the standard nomenclature.

Figure 3 shows the implications of $P$ and $Q$ through a binary phase diagram ${ }^{36}$. The supercooling parameter $P$ is the amount of undercooling present when steady state growth is attained as shown in Figure 2. Quested et al ${ }^{36}$ indicated that $Q$ could be defined as the available undercooling for the concentration of the initial solid to form.

The importance of $Q$ is further shown by Eq. [3] below. $Q$ is equivalent to the initial rate of development of supercooling with respect to fraction solid, i.e.

$Q=\left|\frac{d T c}{d f_{S}}\right|_{f s \rightarrow 0} 9,29,41,57,58$.

where $\Delta T_{c}=T\left(c_{0}\right)-T\left(c_{l}\right)$, i.e. the liquidus temperature of the alloy minus the liquidus temperature of the new liquid composition after a fraction solid, $f s$, of transformation during solidification. According to this analysis, the difference between $Q$ and $P$ is that $Q$ is the initial rate of supercooling development, later related to the development of supercooling during the initial transient ${ }^{10,43,59}$ and $P$ is the supercooling generated by steady state solidification. This was illustrated previously for the Al-Ti system and presented in Figure 4 9 .

A useful consequence of defining $Q$ as in Eq. [3] is that a thermodynamic approach to predicting the development of supercooling in multi-component alloys was developed $9,36,38$, 58. However, for such alloys the simplest approach is to add the individual element contributions ${ }^{29,30,32}$, i.e.

$Q=\sum_{i} m_{i} c_{0, i}\left(k_{i}-1\right)$

which was extended to include the diffusivities of the individual alloying elements ${ }^{60}$. This expression is effective in many ${ }^{30,32,45}$, but not all situations $9,54,61$. Eq. [3] has led to significant insights into how the grain size may deviate from Eq. [4] using computational thermodynamic calculations ${ }^{62}$.

To compare the effects of $Q$ and $P$ on the grain size, relative values for typical alloying elements added to $\mathrm{Al}$ are provided in Table I. Because of the similarity between $P$ and $Q$ for a particular system there is a similar trend in grain size; as $C_{o}$ increases the grain size decreases. In many cases the relative changes between using $P$ or $Q$ as a Supercooling parameter are also similar. However, this table highlights that Al-Ti is the system where there is a distinct difference between $P$ and $Q$ in the relative effectiveness of grain refinement for a 
unit concentration of the element, where the $Q$ value far exceeds that of the other alloys whilst $P$ does not. It is clear that even for similar $Q$ values, Ti is a much more effective solute at reducing grain size than any other alloying addition to $\mathrm{Al}$ alloys and in particular $\mathrm{Si}$ which has a much lower relative $Q$ value than Ti but a higher relative $P$ value ${ }^{30,50}$. It is well established that the reduction of grain size by an addition of $\mathrm{Ti}$ is far greater than other alloying elements ${ }^{3}$ in particular Si for a similar concentration ${ }^{8,30,63}$.

There is an ongoing discussion as to whether $P$ or $Q$ better represents the relationship between alloy composition and the grain size data. Whilst initially $P$ was generally used ${ }^{27,44}$, ${ }^{64}$, more recently $Q$ has been preferred for various experimental and theoretical reasons ${ }^{9,41}$,

51. However, even very recently, the idea that it is the total solidification range that controls grain refinement has been published in the literature ${ }^{65}$ in an attempt to explain the grain size coarsening that occurs in some systems such as $\mathrm{Al}-\mathrm{Si}^{32,53}$. It was found that their experimental data for Al-Cu supported the use of $P^{65}$. However, the increase in grain size observed at the highest $\mathrm{Cu}$ content used in the Al-Cu system by Birol ${ }^{65}$ has not been observed by other authors ${ }^{66}$. An insightful approach by Schempp et al ${ }^{67}$ related $P$ to the columnar to equiaxed transition where it may be that the total supercooling is important, and $Q$ to the grain size in the weld zones in Al-based alloys.

The grain size, $d_{g s}$, for a wide range of alloys ${ }^{45,68}$ and solidification conditions with different cooling rates ${ }^{69,70}$ ranging from slowly cooled laboratory castings to high pressure die casting ${ }^{71}$, ultrasonic treatment of melts ${ }^{7,49,72}$, and welding ${ }^{67}$, can be related to $Q$ through the relationship

$d_{g s}=a+b / Q$

where $a$ and $b$ are constants which depend upon the nucleant particle density, $a$, the nucleation undercooling, solute diffusion rate and growth velocity, $b$. It is surprising that this relationship also applies to non-equilibrium situations as $Q$ is derived from equilibrium phase diagrams. A detailed analysis of $Q$ is given elsewhere ${ }^{54}$. Eq. [5] was first appreciated as an empirical relationship ${ }^{32}$ but a recent theoretical analysis has revealed that it holds on a rigorous basis ${ }^{43}$.

In summary, the parameter which best quantifies the effect of CS on nucleation for each alloy is the growth restriction factor $Q$ and the larger the value of $Q$ the greater the grain refining capacity of an alloy will be. This is because $Q$ defines the rate at which CS is generated and a faster rate of CS development allows further nucleation events to occur sooner producing a finer equiaxed structure. However, to develop an accurate predictor of grain size, understanding the parameters from theory that affect the final as-cast grain size is required and this is the focus of the next section.

The next section describes the development of CS during the initial transient of solidification and how it promotes nucleation on potent particles. Once the importance of CS in promoting 
refinement is established, the factors limiting further refinement are explored. Finally, the role of CS in protecting the newly formed grains is discussed.

\section{CONSTITUTIONAL SUPERCOOLING PROMOTES NUCLEATION}

The very first nucleation events are expected to be caused by thermal undercooling near the mould walls of the casting where the rate of heat extraction is initially high ${ }^{73,74}$. The mould walls are then rapidly heated and the temperature gradient decreases to become almost flat. For pure metals, grains are nucleated and form on, or very near to, the mould wall where the rapid generation of thermal undercooling can trigger nucleation of grains, which then grow as columnar grains towards the thermal centre of the casting. The reason no equiaxed grains are formed is that there is no driving force for nucleation ahead of the columnar grains where the $\mathrm{S}-\mathrm{L}$ interface is at the melting point of the metal with hotter liquid ahead of the interface. Any free crystallites floating in the melt are easily remelted by small increases in temperature due to grains floating into hotter liquid or to convection of hotter liquid from the centre of the casting to the cooler regions towards the walls of the castings. This means that very special conditions are required to produce an equiaxed structure in a pure metal ${ }^{75}$.

In alloys, the driving force for nucleation in the bulk of the melt is generated by the formation of CS which is formed at the interface of the already growing grains which are either free crystals or columnar grains formed due to thermal undercooling. Once the developing CS exceeds the undercooling required for nucleation on a potent particle, $\Delta T_{n}$, then nucleation of equiaxed grains occurs.

Figure 5 illustrates the formation of CS in front of a growing grain's S-L interface. The difference between $T_{E}$ and the actual temperature of the melt, $T_{A}$, is the amount of CS, $\Delta T_{C S}$, generated which changes from zero at the S-L interface to a maximum value at the end of the diffusion field where $C_{l}$ becomes equal to $C_{o}$. In terms of generating sufficient $\Delta T_{C S}$ to trigger nucleation on a particle with a nucleation undercooling of $\Delta T_{n}$, there are two important distances that need to be quantified. One is the amount of grain growth, $x_{C S}$, required to generate a CS zone and the other is the length of the diffusion field, $x^{\prime} d l$, to the point where $\Delta T_{C S}$ exceeds $\Delta T_{n}$.

The other important thing to note in Figure 5 is that the gradient of $T_{A}$ in front of an equiaxed grain is initially negative as the latent heat generated by grain growth is extracted by the surrounding liquid. Because thermal diffusion is relatively fast, this gradient will be low. Also, heat will flow towards this zone from the hotter liquid ahead of the growing grain. The two thermal fields overlap reducing the thermal gradient in front of the S-L interface. The amount of thermal undercooling, $\Delta T_{t}$, in front of a grain in a low temperature gradient will be small compared to that provided by CS. The schematic representation in Figure 4 exaggerates the size of $\Delta T_{t}$ relative to $\Delta T_{C S}$ but is illustrated to keep in mind that this thermal field exists even though it might be essentially negligible. 
The extent of the CS zone, $\Delta T_{C S}$ and $x^{\prime}{ }_{d l}$, is the major factor creating the conditions for nucleation. $\Delta T_{C S}$ is determined by $x_{C S}$ and $x^{\prime}{ }_{d l}$ is determined by the size of the diffusion field in front of the growing grain. Together $x_{C S}$ and $x^{\prime}{ }_{d l}$ define a Nucleation-Free Zone (NFZ) ${ }^{10}$. These lengths contribute to the final grain size as shown by the Interdependence equation:

$$
d_{\mathrm{gs}}=\frac{D z \Delta T_{\mathrm{n}}}{v Q}+\frac{4.6 D}{v}\left(\frac{C_{1}^{*}-C_{0}}{C_{1}^{*}(1-k)}\right)+x_{\mathrm{sd}}
$$

where $D$ is the diffusion rate in the liquid, $v$ the initial growth rate of the S-L interface and $k$ is the partition coefficient. $x_{C S}$ is calculated by the first term in equation 6 and the composition of the liquid at the interface, $C_{l}^{*}$, is used to calculate $x^{\prime}{ }_{d l}$ by the second term.

It is important to note that nucleation occurs during the initial transient of solidification on the most potent particles as nucleation can occur within a fraction of a degree below the liquidus requiring only a small amount of CS to be developed. The magnitude of the CS zone is defined by the length of the CS zone $x^{\prime}{ }_{d l}$ and the depth of the zone between $T_{E}$ and $T_{A}$.

CS develops during the initial growth of grains as shown in Figure 6. The initial nucleation events for an alloy of composition $C_{o}$, occur early in the initial transient between the liquidus and solidus temperatures. Once the temperature reaches the solidus, growth of grains continues under steady state conditions when the alloy composition of the solid forming equals $C_{o}$. Figure 6 shows that during the initial transient, the compositions of the solid and liquid follow the solidus and liquidus lines from $T_{E}\left(C_{o}\right)$ to $T_{3}$ when steady-state growth occurs. As nucleation when potent particles are present occurs early in the initial transient we can ignore the subsequent solidification beyond a few degrees below the liquidus (e.g. $t_{1}$ and $t_{2}$ in Figure 6). That is, when nucleation is occurring the system is a long way from achieving steady-state growth.

For accurate prediction of grain size to be possible the characteristics of the nucleant particles need to be described. To relate these characteristics to the development of CS the potency and distribution of particle size are defined by their thermal and size characteristics: $\Delta T_{n}$ and $x_{S d}$ for each particle size. By converting each particle of size $d$ to $\Delta T_{n}{ }^{41}$ and calculating the average distance, $x_{S d}$, between particles of the same size and plotting $\Delta T_{n}$ against $x_{S d}$ produces a $\Delta T_{n}-S_{d}$ curve ${ }^{10}$ as illustrated in Figure 7 . The $\Delta T_{n}-S_{d}$ curve shifts to the left as the amount of master alloy is increased thereby decreasing $x_{S d}$.

By combining the thermal information for $\Delta T_{C S}$ and $\Delta T_{n}-S d$ as illustrated in Figure 7, it is possible to schematically determine when and where a nucleation event will occur. The location of a new nucleation event is the point where the $T_{A}$ curve intersects the $\Delta T_{n}-S d$ curve. The distance from this point to the previous nucleation point is an indication of the average grain diameter, $d_{g s}$. This schematic representation forms the basis of the Interdependence Theory ${ }^{10}$ and Eq. [6]. 
Each term in Eq. [6] defines the distances $x_{C S}, x_{d l}^{\prime}$ and $x_{S d}$ as illustrated in Figure 7(a). Eq. [6] can be simplified to Eq. [7] ${ }^{59}$.

$d_{g s}=5.6\left(\frac{D \cdot z \Delta T_{n}}{v \cdot Q}\right)+x_{S d}$

noting the similarity with Equation 5.

The term $z$ in Eqs. [6] and [7] relates to the fact that each new nucleation event only needs a fraction of the total CS (equal to $\Delta T_{n}$ ) to be generated as the liquid at that point is already constitutionally supercooled (Figure 8). $z$ is related to the temperature gradient ahead of the S-L interface as shown in Figure 7 and represents the incremental increase in CS as the gradient of $T_{A}$ progresses to lower temperatures as the melt cools.

Figures 7 and 8 assume that nucleation occurs on the most potent particles. Therefore, nucleation occurs in a wave of nucleation events as the temperature gradient moves through the liquid. Each event is triggered when $T_{A}=T_{n}$. This hypothesis was recently supported by real-time X-ray studies of Al-Si alloys where a wave of nucleation events are observed to appear as the temperature gradient moves across the field of view ${ }^{76}$.

Figure 7(b) shows the effect of $Q$ on the three distances in Eq. [6] that define the grain size. At infinite $Q, \mathrm{NFZ}$ is zero and the grain size is set by $x_{S d}$. For each alloy composition the theoretical limit of refinement is given by $x_{n f z}$. For low $Q$ values NFZ can contribute $50 \%$ or more to the grain size ${ }^{10,77}$. Figure 7(b) assumes a constant particle number density for all values of $Q$. If the particle number density also changes with each increment in $Q$ then the value of $x_{S d}$ changes with $Q$ as discussed previously ${ }^{77}$..

This section has highlighted how CS promotes nucleation but it also showed that the formation of NFZ can significantly contribute to the final grain size by preventing many potent particles becoming active nucleants. NFZ and other factors that affect the activation of potent particles are discussed in the following section.

\section{FACTORS THAT AFFECT THE EXTENT OF THE NUCLEATION FREE ZONE}

There are three factors that reduce the likelihood of nucleation occurring. These are the formation of a nucleation-free zone (NFZ) as described by Eq. [6], the potency distribution of the nucleant particles and solute accumulation which occurs between adjacent previously nucleated grains. These factors are actually interrelated and extend our concept of NFZ. The length of the diffusion field, $x^{\prime}{ }_{d l}$, is the dominant contributor to the size of NFZ (Eq. [6]) and can be extended to cover the region between adjacent grains by solute accumulation due to overlapping diffusion fields. That is, once the diffusion fields overlap NFZ is established at all points between the adjacent grains. These factors together create a situation where nucleation is not able to occur because the value of $\Delta T_{C S}$ is less than $\Delta T_{\mathrm{n}}$. 
As indicated in Figure 7(b) and illustrated in Fig. 9, NFZ is formed around each growing grain. The length of this zone is the second component of NFZ $x^{\prime}{ }_{d l}$ (Eq. [6]) and corresponds to the length of the diffusion field between $C_{l}^{*}$ at the S-L interface and $C_{o}$ where $\Delta T_{C S}$ is at a maximum value (Figure 5). Because $x^{\prime}{ }_{d l}$ is much larger than $x_{C S}$ the predicted grain size is very sensitive to this term and it is therefore important to consider how $x^{\prime}{ }_{d l}^{\prime}$ is calculated. Due to the importance of the diffusion field three recent analytical approaches are compared with the case of dendritic growth calculated by a numerical model to determine the differences in the length of the diffusion field produced by each method to determine the relative accuracy of each approach in predicting grain size. Each model defines this length differently and for consistency we will define them generically as $x_{d l}$ in the following discussion.

\section{Calculation of the size of the diffusion field}

The Interdependence model's prediction of the diffusion field is compared with two numerical models by Shu et al ${ }^{78}$ and $\mathrm{Du}$ and $\mathrm{Li}^{79}$ respectively. All three models recognize the importance of a region where nucleation cannot occur due to the formation of the solute diffusion field ahead of the growing S-L interface. The length of $x_{d l}$ where nucleation cannot take place is governed by the changing solute concentration ahead of the S-L interface. This change in the solute content with distance from the interface is usually modelled using an exponential function and from this the distance $x_{d l}$ within which no nucleation can take place can be estimated. $x_{d l}$ is termed differently in the three models ( $x_{d l}^{\prime}$ in the Interdependence model, $w^{*}$ in the Shu et al model and $r^{*}$ in the Du-Li model), however all agree that this distance, among other factors such as inoculant separation distance and the amount of grain growth, governs the eventual grain size. In the following we compare the predictions of $x_{d l}$ by the three models.

The salient features of the three models are as follows.

i. The Interdependence model assumes that an equiaxed dendritic grain grows with a rate $v$. It assumes a 2-D planar interface for solute diffusion. The transient nature of solute diffusion is taken into account by using the Trivedi-Kurz approximation ${ }^{83}$.

ii. The Shu et al model ${ }^{84}$ is based on a 3D equiaxed spherical grain based on the RappazThevoz (R-T) model of equiaxed grain growth ${ }^{85}$, the solute diffusion equations being the same as described in the R-T model. In the R-T model, within the grain the solute diffusion equations are for spherical growth, however, solute diffusion from the S-L interface assumes a 2D steady-state planar interface. These equations are the analytical solution to 'steady-state diffusion equation from a moving planar interface' used originally by Tiller et $\mathrm{al}^{14}$ and described by Kurz-Fisher ${ }^{56}$. For this case also, the solute diffusion equation yields an analytical solution.

iii. The Du-Li model ${ }^{79}$ is also for a 3D spherical grain but for a multicomponent alloy system. Their paper provides limited information on the conceptual framework on which their model is based, hence it is difficult to comment on their model formulation with certainty. However, the following was deduced. The grain growth seems to follow the 
Kampmann-Wagner model ${ }^{86}$ with adaptions from the Maxwell-Hellawell model ${ }^{28}$. Solute diffusion within the grain follows along the lines of the Shu et al model. Diffusion from the S-L interface is modelled for the case of 3D growth of a precipitate as described by the stationary interface approximation ${ }^{79}$. The grain growth model having been adapted from the invariant-field approximated growth of a spherical precipitate in a matrix as described by Aaron-Fainstein-Kotler ${ }^{80}$. This in turn is adapted from Mullins$\underline{\text { Sekerka }}{ }^{81}$ and Corriell-Parker ${ }^{82}$. The solution using the invariant-field approximation is based on setting the time-dependent term, $\mathrm{dC} / \mathrm{dt}=0$, and then solving the resulting steady-state Laplace equation ${ }^{80}$. It assumes a $2 \mathrm{D}$ planar interface for solute diffusion ahead of the interface. An analytical solution is obtained for the approximated solute diffusion equation.

It should however be noted that the diffusion equations used in the numerical models of Shu et al and Du-Li are analytical in nature and will be treated as such in this analysis for the purpose of comparison between the models.

The final equations for calculating $x_{d l}$ by the three models are given below.

Interdependence model: $x_{d l}^{\prime}=\frac{4.6 D}{v}\left(\frac{C_{l}^{*}-C_{0}}{C_{l}^{*}(1-k)}\right)$

Shu et al model: $w^{*}=\frac{\Delta T_{n}+\Delta T_{c S}-\Delta T}{\Delta T_{c S}} \delta_{c}$

Du-Li model: $r^{*}=\Delta T_{c S} \frac{r^{0}}{\Delta T-\Delta T_{n}}$

The terms in Eq. [8] for the Interdependence model are the same as explained above. In the Shu et al model, $\Delta T$ is the total undercooling $\left(=\Delta T_{r}+\Delta T_{c s}+\Delta T_{t}\right), \Delta T_{c s}$ is the constitutional supercooling, and $\delta_{c}$ is the solute diffusion boundary layer ahead of the interface. Shu et al used $\Delta T_{f g}$ for the nucleation undercooling based on the free-growth nucleation theory developed by Greer ${ }^{41}$, which is $\Delta T_{n}$ used in the Interdependence model. For consistency during comparison, $\Delta T_{n}$ replaces $\Delta T_{f g}$ in the Shu et al model described by Eq. [9]. In the DuLi model, the terms are the same as in the Shu et al model with the extra $r^{0}$ term representing the grain envelope radius. In both cases, the grain envelope is assumed to be spherical with the equiaxed grain contained within the envelope. Thus the envelope is the locus of the dendrite tips which grow equiaxially at some rate $v$. Finally, the Interdependence model results were also compared against the results from the numerical solidification model, $\mu$ MatIC. Calculations for the different models are explained in the Appendix. Here, only the results from the calculations are shown followed by discussion.

Figure 10 shows the comparison between the Interdependence model and the $\mu$ MatIC model. $x_{d l}$ is plotted as a function of the nucleation undercooling. Note that in the isothermal $\mu \mathrm{MatIC}$ model, a cooling rate was imposed that results in a drop in the domain temperature with every time step. Thus, the undercooling in the $\mu$ MatIC model is the difference between the alloy 
liquidus and the domain temperature at any given time step. Very early during grain growth the undercooling would be small then increase with time.

A number of different constant growth rate values were used for the Interdependence model. The values of $x_{d l}$ obtained from the Interdependence model are linear while that from the $\mu$ MatIC model is curved, starting at a higher value initially. The plot shows that in the early stages, the Interdependence model under-estimates $x_{d l}$ for growth rates greater than $1 \mu \mathrm{m} / \mathrm{s}$ compared to the numerical model. Given the inverse relationship between $x^{\prime} d l$ and growth rate (Eq. [7]), this suggests that early in growth the growth rates in the $\mu$ MatIC model are lower compared to that used in the Interdependence model. The growth rate in the numerical model then increases as the undercooling increases (from $2 \mu \mathrm{m} / \mathrm{s}$ at $\Delta T_{n}=0.5 \mathrm{~K}$ to $14 \mu \mathrm{m} / \mathrm{s}$ at $\Delta T_{n}=2 \mathrm{~K}$ ). This continuous increase in $v$ results in a continuous decrease in the rate of change in $x_{d l}$ and intersects with the $x_{d l}$ lines calculated from the Interdependence model at higher undercoolings. Furthermore, it appears that the growth rate of $2 \mu \mathrm{m} / \mathrm{s}$ used for validation of the Interdependence model was a reasonable value to choose ${ }^{10}$. The higher growth rate values used in the Interdependence model gives lower values of $x^{\prime} d l$ in the early stages of growth at low undercoolings.

Figure 11 plots the $x_{d l}$ values calculated by the three analytical models as a function of undercooling. Both the Shu et al and Du-Li models give much larger values compared to the Interdependence model. Du-Li have also reported that the Shu et al model overestimates $x_{d l}$ 79 . However, our analysis indicates that this is true only in the very early stages of low undercooling (up to $\sim 0.35 \mathrm{~K}$ ). Beyond this, the Du-Li model results exceed the Shu et al results by an increasing margin. One possible reason for this increase could be the grain envelope term $r^{0}$ that increases very quickly with increasing undercooling. The results from the Shu et al and Du-Li models are also significantly higher than that from the $\mu$ MatIC model. On the other hand, the Interdependence model shows reasonable agreement with the $\mu$ MatIC model results in Figure 10. This may be attributed to the supersaturation term, $\Omega=$ $\left(\frac{C_{l}^{*}-C_{0}}{C_{l}^{*}-C_{s}^{*}}\right)$, used in the calculations which takes into account the transient interface composition $C_{l}^{*}$ during the initial transient.

The analysis presented in the Appendix shows that the $\Delta T_{r}$ and $\Delta T_{t}$ terms are very small compared to the $\Delta T_{c s}$ term. Thus $\Delta T_{c s} \cong \Delta T$ in the numerator in the Shu et al model (Eq. [9]), and $w^{*}$ becomes only a function of $\Delta T_{n} / \Delta T_{c s}$ and $\delta_{c}$. As the undercooling goes from smaller to larger values, the $\Delta T_{n} / \Delta T_{c s}$ term assumes an almost constant value, resulting in a fixed value for $w^{*}$. This is shown in Figure 11(b). Note that, based on a steady-state planar interface, $\delta_{c}$ is a constant depending only upon solute diffusion in the liquid, $D$, and the growth rate, $v$.

In light of the fact that $\Delta T_{c s} \cong \Delta T$ (which is an assumption used by the authors of all three models in their calculations recognising the dominance of $\Delta T_{c s}$ over other forms of 
supercooling in most casting situations ${ }^{1}$ ), and using the definition of supersaturation, $\Omega$, the equations [8] - [10] may be rewritten as follows, which allows for a further comparison between the three models:

Interdependence model: $x_{d l}^{\prime}=\frac{4.6 D}{v} \Omega$

Using the assumption that $\Delta T_{c s} \cong \Delta T_{n}$ from the Interdependence model, it may be further rewritten as:

Interdependence model: $x_{d l}^{\prime}=\frac{4.6 D}{v} \Omega \frac{\Delta T_{n}}{\Delta T_{c S}}$

Shu et al model: $w^{*}=\frac{2 D}{v} \frac{\Delta T_{n}}{\Delta T_{c s}}$

Du-Li model: $r^{*}=\frac{D}{v} \Omega \frac{1}{1-\frac{\Delta T_{n}}{\Delta T_{c S}}}$

Since $\Delta T_{c s}$ is the major contributor to the total undercooling, it is reasonable to expect that $\Delta T_{c s} \cong \Delta T_{n}$. For this case, the Shu et al model reduces to the same value as the diffusion length for the $2 \mathrm{D}$ planar interface under steady-state $\left(\delta_{c}=\frac{2 D}{v}\right)$. On the other hand, for $\Delta T_{c s} \cong$ $\Delta T_{n}$ the Du-Li model results in $r^{*} \rightarrow \infty$. This also explains the extremely large $x_{d l}$ values from these models, particularly the Du-Li result which increases rapidly.

Another way to look at the Shu et al model is that under steady state $\Omega=1$ and therefore their model may be re-written as:

Shu et al model: $w^{*}=\frac{2 D}{v} \Omega \frac{\Delta T_{n}}{\Delta T_{c S}}$

There is a significant similarity between the Interdependence and the Shu et al models (Eqs. [12] and [15]) with the difference being in the constant term (2 for the Shu et al model and 4.6 for the Interdependence model). Under the steady state condition, the Shu et al model would give a smaller value for $x_{d l}$ than the Interdependence model. However, the initial transient is not captured in the Shu et al model as $\Omega$ is equal to 1 . On the other hand, the DuLi model seems to capture the initial transient, but yields very large values owing to the fact that $\Delta T_{n}$ is close to $\Delta T_{c s}$, and in fact, will fail when the condition $\Delta T_{n}=\Delta T_{c s}$ is reached.

However, the important point gleaned from the Du-Li model is that the condition $\Delta T_{n}<\Delta T_{c s}$ should always be valid, otherwise $r^{*}$ becomes negative. Combining this condition with $\Delta T_{n}$

\footnotetext{
1 This assumption is likely to break down at very high cooling rates where numerical approaches would be superior to analytical approaches in dealing with the more complex situation where thermal undercooling also is significant. The curvature undercooling is also negligible under conventional casting conditions although becomes significant for crystallites in the nanometer length scale.
} 
being close to $\Delta T_{c s}$, the $\Delta T_{c s} \cong \Delta T_{n}$ assumption made in the Interdependence model is reasonable.

The above analysis shows that the four models produce a broad range of results. For example, if we assume $\Delta T_{n}$ is $0.2^{\circ} \mathrm{C}$ and the values of $v$ and $D$ are the same for the three analytical models, the respective values of $x_{d l}$ are $24 \mu \mathrm{m}$ for the Interdependence model for $v=2 \mu \mathrm{m} / \mathrm{s}$, $61 \mu \mathrm{m}$ for the $\mu \mathrm{MatIC}$ model, $308 \mu \mathrm{m}$ for the Du-Li model and $1947 \mu \mathrm{m}$ for the Shu et al model. If $v$ is reduced to $1 \mu \mathrm{m} / \mathrm{s}$ the Interdependence and $\mu$ MatIC models produce close to the same result with $47 \mu \mathrm{m}$ for $x^{\prime} d l$. The Interdependence and $\mu$ MatIC models predict $x_{d l}$ values of the same order of magnitude. The other predictions are one order and two orders of magnitude greater, respectively. However, a significant issue in comparing models is that the input data for $v, D$ and $\Delta T_{n}$ available in the literature are all imprecise and can vary considerably ${ }^{10}$. Unlike the Shu et al and Du-Li models the Interdependence model includes the term $x_{S d}$ which also contributes to the final grain size (Eq. [6]).

\section{The effect of solute accumulation on NFZ}

Figure 12 illustrates the development of solute accumulation between two adjacent grains due to the interaction of the diffusion fields arising from each grain. Once the diffusion fields overlap solute begins to accumulate. Recent numerical modelling of the grain growth process ${ }^{11}$ showed that during the initial transient $\Delta T_{C S}$ initially increases and then decreases as illustrated in Figure 9. The modelling showed that the point at which $\Delta T_{C S}$ begins to decrease is not necessarily when solute accumulation begins as $T_{A}$ is also decreasing at a rate dependent on the cooling rate. However, the rate of accumulation eventually increases the composition above $C_{o}$ at a faster rate than $T_{A}$ decreases and, therefore, $\Delta T_{C S}$ decreases because the maximum value of $T_{E}$ decreases towards $T_{A}$. When the separation distance between grains is small $\Delta T_{C S}$ begins to decrease almost immediately while when they are far apart $\Delta T_{C S}$ formed between the grains may be sufficient to trigger another nucleation event. However, unless a suitable particle is present it is more likely that no further nucleation occurs after the initial wave of nucleation events occurs. This situation is shown in Figure 13, real-time $\mathrm{x}$-ray of the nucleation and growth of an Al-4wt.\%Si alloy, where nucleation is complete within a few seconds of the first observed grain and that growth is almost complete within 7 seconds with no further nucleation events occurring. This observation is consistent with the regular grain size often observed in the equiaxed zone of castings.

\section{CONSTITUTIONAL SUPERCOOLING PROTECTS GRAIN FORMATION}

This section discusses the role of CS in ensuring the newly nucleated grains survive and grow. It has been understood for some time that CS contributes to the survival of equiaxed grains ${ }^{87}$. However, with the more complete understanding we now have regarding the role of $\mathrm{CS}$ in grain formation it is useful to look into the role of CS in protecting newly nucleated equiaxed grains in more depth. 
When considering the likelihood of grain survival there are two other factors to consider. One is the temperature gradient and the other is convection. The temperature gradient is important as a steep temperature gradient means that the liquid ahead of the S-L interface is hotter and new grains that move ahead of the interface are more likely to be in a superheated region increasing the probability of remelting. During the actual casting process there are degrees of turbulence and thermal and solutal convection. Turbulence (strong fluid convention) arises from the pouring process and can still be prevalent when nucleation begins. Examples include simple direct pour ingot casting, high-pressure die-casting and when external fields are applied. In processes such as low pressure die-casting and direct chill casting turbulence is minimised, however, thermal convection continues to be active during the nucleation process. Also, convection is accompanied by thermal and compositional diffusion processes. The combination of the above actions determine not only when and where nucleation occurs but it also determines the likelihood of survival of the crystals formed and how they are transported throughout the casting.

When nucleation occurs while significant turbulence from pouring is still present, it is likely that the temperature gradient from the casting wall to the centre of the casting is relatively steep ${ }^{74,88}$. In this case grains that form near the colder mould walls will be transported into hotter liquid and remelt. It is seen in Figure $14{ }^{89}$ that a high superheat $(65 \mathrm{~K})$ even with a cold mould wall does not lead to substantial grain refinement due to re-melting. At the lower superheat of $35 \mathrm{~K}$ substantially more nucleation events survive. Hence, it is clear that a colder mould wall substantially increases the number of nucleation events at a similar cooling rate of casting at low superheats $(35 \mathrm{~K})$. It is clear that the role of solute is very similar in each case with a greater solute content leading to a substantially smaller grain size. As the melt becomes more quiescent the temperature gradient also decreases improving the likelihood of grain survival. The important temperatures that need to be considered are the actual gradient of $T_{A}$ in the liquid, the equilibrium liquidus temperature, $T_{E}$, and the nucleation temperature of the potent particles, $T_{n}$. The important region is where $T_{E}$ is greater than $T_{A}$, i.e. the CS zone. The following describes three different situations and the likelihood of grain survival in each of them.

Pure metal grains are not protected: Figure 15(a) is a schematic representing a crystal of pure metal formed from pure liquid with an interfacial temperature close to the melting point $T_{M P}\left(=T_{E}\right)$. Growth is controlled by the point of balance between the release of latent heat and heat extraction. The dashed lines represent $T_{A}$ when stable growth is occurring and when convection brings the hotter liquid to the $\mathrm{S}$ - $\mathrm{L}$ interface causing the temperature to rise above $T_{M P}$ and the grain will begin melting. In this situation, new grains can be readily remelted and the normal structure produced is columnar. This means that there were negligible nucleation events in the liquid ahead of the growing columnar front that survive. However, equiaxed grains as illustrated in Figure 15(a), can be produced within the bulk of the melt by the application of an external field ${ }^{75}$. For these grains to be stable the temperature of the grains needs to remain below the melting point implying a very low temperature gradient in the melt 75 . 
Directional growth of alloy dendrites provides some protection: Figure 15(b) is a schematic of the situation during directional growth of an alloy where the CS zone is present for a limited distance in front of the S-L. This CS Zone provides some protection to the growing grain as thermodynamically, solidification is preferred over remelting adjacent to the interface. If new grains are nucleated ahead of the S-L interface or are released by fragmentation of dendrites and then float out of the CS zone they will remelt. Also, if thermal convection brings the hotter liquid towards the interface then the CS driving force for growth is reduced or even eliminated and needs to be re-established for growth to continue. This may cause growth to stop for a moment before beginning again. Mirihanage et al ${ }^{90}$ observed this effect during real-time x-ray studies of the directional solidification of an Al-Cu alloy.

Alloy grains in a CS melt are protected: Figure 15(c) is a schematic of the case when the CS zone extends well beyond the S-L interface. This situation would be typical of equiaxed growth in a low temperature gradient melt. There are two profiles for $T_{E}$ representing a point in time for two alloys of differing $Q$ values. As shown earlier in Figure 3 and Eq. [3] a larger $Q$ value generates CS more rapidly and therefore increases the likelihood of survival for newly nucleated grains. When the temperature gradient $T_{A}$ is very low most of the melt will be constitutionally supercooled and therefore grains can move in the melt without the risk of remelting. When the long range temperature gradient $T_{A}$ is steeper, it is possible that warmer liquid could be transported to the interface locally increasing $T_{A}$ as represented in Figure 15(d). However, due to the protection of the CS zone complete remelting is unlikely, but growth may be reduced for a moment. If the surrounding cooler liquid is transported towards the $\mathrm{S}$-L interface decreasing $T_{A}$ then growth would monetarily increase to re-establish local equilibrium at the interface. For complete remelting of grains to be possible liquid hotter than $T_{E}$ must be transported some distance to the interface and the larger the value of $Q$ the higher this temperature must be at any given time. This effect is particularly important when the newly formed crystallites are of nanoscale as they could have a much lower melting point than their bulk form due to the Gibbs-Thomson effect. Protection of these crystallites from remelting is important for successful grain refinement. Thus, in the situation of equiaxed solidification the newly nucleated grains are well protected and even better protected as the value of $Q$ increases. This mechanism contributes to achieving a finer grains size in the ascast structure.

\section{INSIGHTS ARISING}

It is clear from the above that the establishment of the CS zone is critical in facilitating the nucleation of grains and their survival. Hence, it is important to understand how CS can be influenced by external factors.

Convection is always present to some degree from quiescent to turbulent and to extremely turbulent in the case of acoustic streaming when ultrasonic treatment is applied. Whether hotter or colder liquid is brought to the interface of growing grains depends on the casting environment. During directional solidification the liquid ahead of the interface is hotter than the growing dendrites, while during equiaxed or free growth of grains the adjacent liquid maybe colder, or at least not hotter than the growing grains, and somewhat hotter towards the 
thermal centre of a casting due to the temperature gradient caused by heat extraction. These local temperature changes due to convection are accompanied by composition change and this will require rebalancing to bring the interface back to local equilibrium. As a result oscillations in the growth rate may occur at the tip of dendrites ${ }^{90}$.

Considering the above, the likelihood of fragmentation is greater during directional solidification than during equiaxed or free growth of grains as the incoming hotter liquid of higher composition can slow growth and allows a degree of remelting. The degree of remelting possible is dependent on the time available which is controlled by the temperature gradient, the morphology of the dendrites and the rate of interface growth. A detailed analysis was recently performed on fragmentation observations revealed by real-time x-ray studies during directional solidification ${ }^{91}$. On the other hand, fragmentation during equiaxed growth is less likely due to the cooler surrounding liquid promoting growth and stabilising the dendritic structure. The chances of hotter liquid reaching the interface are decreased due to the low temperature gradients. In contrast to directional solidification, fragmentation has so far not been observed in real-time $x$-ray of equiaxed grains to the authors' knowledge ${ }^{76}$ unless UT is applied ${ }^{92}$.

The above discussion implies that if the melt can be held below $T_{E}$ (i.e. the liquidus temperature) and $T_{n}$ is above $T_{A}$ then grain survival is ensured. Additionally, if the gradient of $T_{A}$ is low then the CS zone promoting survival is large. A low gradient also reduces the size of NFZ due to a reduction in the value of $z$ in Eqs. [6] and [7] thereby promoting more nucleation events decreasing the grain size further. These points indicate the importance of controlling the casting conditions to create an environment for maximizing nucleation, growth and transport of grains throughout the melt without the risk of remelting. The application of UT is an example where these conditions can be created when the correct parameters are applied ${ }^{93}$.

Evidence supporting the above statement is provided by recent research on the effect of UT on an $\mathrm{Al}-2 \mathrm{Cu}$ alloy with a range of Al3Ti1B master alloy additions ${ }^{94}$. Figure 16 shows that $Q$ has an effect on the grain size obtained from the addition of master alloy without the application of UT. However, when UT is applied the effect of $Q$ is small as the slope of the curve is very low. In the case of ultrasonic treatment acoustic streaming generates a highly turbulent melt which rapidly transfers heat throughout the liquid and into the mould walls resulting in a flattened temperature gradient ${ }^{93}$. This implies that most of the melt will be undercooled at the same time. Considering Eq. [6] and [7], the $z$ term would be close to zero which means that the nucleation-free zone is dramatically reduced. Thus, a significant number of the most potent particles are able to nucleate a grain. The thermal environment generated by UT is essentially the situation described by Winegard and Chalmers in Figure 2.

\section{SUMMARY}

The formation of the CS zone ahead of the growing grains creates a driving force for nucleation ahead of these grains. Higher $Q$ values promote more nucleation by decreasing the size of NFZ and thus the grain size. Only a fraction of the CS required to activate nucleation 
is needed to generate repeated nucleation. Also, a lower temperature gradient reduces the size of NFZ reducing the grain size. All of these factors lead to a finer grain size.

There are four factors that contribute to the size of the nucleation-free zone: $x_{C S}, x^{\prime}{ }_{d l}$, the potency of the activated nucleant particles and solute accumulation. The effect of the nucleation-free zone can be significant depending on the alloy composition as represented by the $Q$ value. For low values of $Q$, NFZ can contribute $50 \%$ or more to the as-cast grain size. Typically there are very few large particles with the highest potency. As the size decreases the potency decreases even faster meaning that most of the particles are not activated. Solute accumulation between already growing grains reduces the amount of CS available for nucleation extending NFZ to cover the region between adjacent grains preventing further nucleation from occurring. For grains close together this situation will occur very quickly. The larger the separation distance between growing grains the more likely additional nucleation will be.

An analysis of analytical equations used in recent models and comparison with a numerical model showed substantial disagreement in predictions of the diffusion field. For low undercooling associated with potent nucleant particles the Interdependence model predicted values similar to the numerical model while the other analytical models predicted orders of magnitude higher values. The cause of these differences appeared to be mostly due to the use of the initial transient in the formulations of the Interdependence model and numerical model and the use of steady state solidification in the other models.

The CS zone surrounding each grain resists the effects of convection allowing grains to survive and grow and this factor may contribute to a finer grain size due to better protection when $Q$ is higher. The degree of protection provided during directional and equiaxed solidification is influenced by the size of the CS zone, alloy composition, temperature gradient, turbulence and thermal and compositional convection. Considering the likely effects of these factors it is proposed that fragmentation is more likely to occur during directional solidification than during equiaxed solidification; that oscillations in growth rate can occur due to convection affecting the interfacial temperature or composition causing the growth rate to increase or decrease to return the interface compositions to local equilibrium; and in the extreme case created by the application of external fields can create an environment that maximises nucleation and survival of grains to produce a fine equiaxed structure throughout a casting.

\section{APPENDIX}

Calculations for the Interdependence model: To calculate $x_{d l}$, the Interdependence model requires that the growth rate, $v$, and the nucleation undercooling, $\Delta T_{n}\left(=\Delta T_{c s}\right)$, in the solidifying grain be user-defined for a given alloy system (in our case $\mathrm{Al}-7 \mathrm{Si}$, the property and phase diagram values used are shown in Table II). The $C_{l}^{*}$ term is then evaluated using the definition of $\Delta T_{c s}$. Thus, a set of critical distances was generated for a combination of $\Delta T_{n}$ 
and $v$ values. In order to compare the different models, the same values of $\Delta T_{n}$ and $v$ were used in the Shu et al and Du-Li models.

Calculations for the Shu et al model ${ }^{84}$ : The Shu et al model requires evaluating the total undercooling, $\Delta T$, which additionally includes $\Delta T_{r}$ (radius undercooling) and $\Delta T_{t}$ (thermal undercooling). For the dendritic shape of the equiaxed grain, estimating the radius of the growing dendrite, $R_{d}$, is critical in evaluating the three components of the total undercooling. Recall that $\Delta T_{n}$ and $C_{l}^{*}$ are already known from the Interdependence model. $\Delta T_{c}$ requires $C_{l}^{*}$ as well as the solution to the problem of diffusion from a parabolic tip given as the Ivantsov solution, $I v(P)^{95}$, where $\mathrm{P}$ represents the appropriate Peclet number for solute or heat diffusion. Eq. [16] shows the correlation between $\Delta T_{c s}, C_{l} *$ and $I v\left(P_{c}\right)$.

$\Delta T_{c S}=m\left(C_{0}-C_{l}^{*}\right)=m C_{0}\left(1-\frac{1}{1-(1-k) I v\left(P_{c}\right)}\right)$

The Ivantsov solution in the case of constitutional supercooling is a function of the solutal Peclet number, $\mathrm{P}_{\mathrm{c}}\left(=v R_{d} /(2 D)\right)$, and $D$ is the solute diffusion coefficient. $I v\left(P_{c}\right)$ can be written in terms of the $P_{c}$ number ${ }^{56}$. This approach of using the Ivantsov solution for equiaxed grain growth has been used for modelling the grain growth from a single nucleation site within a single atomized Al-Cu droplet ${ }^{96}$. From the Ivantsov solution for a given $\Delta T_{C S}$, the $P_{c}$ value is obtained based on linear interpolation on the $P_{c}-I v\left(P_{c}\right)$ table, generated for a range of $P_{c}$ numbers. Subsequently, the dendrite tip radius, $R_{d}$, is calculated using the definition of the $P_{c}$ number. The $\Delta T_{r}$ and $\Delta T_{t}$ terms can now be evaluated using the equations given below.

$$
\begin{aligned}
& \Delta T_{r}=\frac{2 \Gamma}{R_{d} \Delta T_{f r}} \\
& \Delta T_{t}=\frac{L}{C_{p}} \operatorname{Iv}\left(P_{t}\right)
\end{aligned}
$$

Here $\Gamma$ is the interfacial energy term, $\Delta T_{f r}$ is the freezing range, $L$ is the latent heat of fusion, $C_{p}$ the specific heat and $I v\left(P_{t}\right)$ is the solution to the heat diffusion from a parabolic tip, where $P_{t}$ is the thermal Peclet number $\left(=v R_{d} /(2 \alpha)\right), \alpha$ being the rate of thermal diffusion.

Finally, $\delta_{c}$ is calculated based on Eq. 2 in Shu et $\mathrm{al}^{84}$. Interestingly, although the grain growth is considered to be spherical, the $\delta_{c}$ term is actually based on a steady-state planar interface ${ }^{97}$. Note that the Interdependence model also uses a planar interface approximation for the SL interface, but with a transient analysis with the $C_{l}^{*}$ term included.

Calculations for the Du-Li model: The $\Delta T_{c s}$ and $\Delta T$ terms are the same as in the Shu et al model and therefore the same method was applied as before to calculate these terms. There is an additional $r^{0}$ term which is the amount of growth of the grain envelope. To evaluate this term Eq. 4(a) in ${ }^{79}$ was used. 
$R=\frac{D \Omega}{v}$

Eq. [19] relates the amount of grain growth to the solute super saturation, $\Omega\left(=\left(\frac{C_{l}^{*}-C_{0}}{C_{l}^{*}(1-k)}\right)\right)$, ahead of the grain. The supersaturation term requires the $C_{l}^{*}$ term, which is evaluated as before. We believe that $R$ in Eq. 4(a) in their article is the same as $r^{0}$ that was used in the final equation for their calculations of $x_{d l}$. Finally, we have used a binary system, where only one solute species is active. For this case the multicomponent model should be valid as well since the diffusion term for the additional solute species would simply be zero.

\section{Comparison with $\mu$ MatIC:}

The models presented above were all analytical models with certain assumptions such as the diffusion field can be estimated from diffusion in front of a 2D planar interface. The numerical solidification model $\mu$ MatIC, based on CAFD, is used to track the development of the diffusion field. For our case of a single equiaxed grain growing in the centre of the computational domain, the solid grain grows as a dendrite and solute and heat diffusion equations are solved for each cell, both in the liquid and the solid grain. Thus, the distance from the S-L interface where the solute diffusion cut-off criteria of $4.6^{*} l_{D}$ is satisfied can be estimated. Here $l_{D}$ is the characteristic diffusion length as defined by Trivedi and Kurz ${ }^{83}$. The $4.6 * l_{D}$ cut-off criteria has been used in the numerical model since the solute concentration ahead of the interface is known and also because it allows for a direct comparison with the Interdependence model. Note that in this numerical model, the interface is not sharply defined. Hence the interface is approximated as the liquid cell adjacent to the cell representing the solid grain (recognized by the cell composition being $<C_{0}$ ). For the simulation, $1 \mu \mathrm{m}$ cell size was used with periodic boundary conditions. Initially two different domain sizes of 750 and $1000 \mu \mathrm{m}$ were used to assess the effect of edge effects. It was established that $750 \mu \mathrm{m}$ was large enough to avoid the edge effects. The results from these four models (3 analytical and 1 numerical) are compared in figures 10 and 11 in section IV.

\section{ACKNOWLEDGEMENTS}

The authors thank Prof Wilfried Kurz for alerting us to reference ${ }^{12}$ and for his valuable suggestions. We also express our appreciation to Prof Elena Pereloma of the University of Wollongong, Australia for translating reference ${ }^{12}$. The authors acknowledge support from ARC Centre of Excellence for Design in Light Metals, ARC Discovery Projects DP120101672 and DP140100702, and the ExoMet Project co-funded by the European Commission's 7th Framework Programme (contract FP7-NMP3-LA-2012-280421), by the European Space Agency and by the individual partner organisations.

\section{REFERENCES}

1. M.A. Easton and D.H. StJohn: Metall. Mater. Trans. A, 1999. vol. 30A, pp. 16131623. 
2. B.S. Murty, S.A. Kori, and M. Chakraborty: Inter. Mater. Rev., 2002. vol. 47(1), pp. 3-29.

3. A. Cibula: J. Inst. Metals, 1949-50. vol. 76, pp. 321-360.

4. R. Genders and G.L. Bailey: The Casting of Brass Ingots. BNFMR Research Monograph No. 3. 1934, London, 59.

5. H. Hanemann and W. Hofmann: Z. Metallkde., 1937. vol. 29, pp. 149.

6. L. Northcott: J. Inst. Metals, 1939. vol. 65, pp. 173-204.

7. M. Qian, A. Ramirez, A. Das, and D.H. StJohn: J. Cryst. Growth, 2010. vol. 312, pp. 2267-2272.

8. M.A. Easton and D.H. StJohn: Metall. Mater. Trans. A, 1999. vol. 30A, pp. 16251633.

9. M.A. Easton and D.H. StJohn: Acta Mater., 2001. vol. 49(10), pp. 1867-1878.

10. D.H. StJohn, M. Qian, M.A. Easton, and P. Cao: Acta Mater., 2011. vol. 59(12), pp. 4907-4921.

11. A. Prasad, L. Yuan, P.D. Lee, and D.H. StJohn: Acta Mater., 2013. vol. 61(16), pp. 5914-5927.

12. G.P. Ivantzov: Proceedings of the Academy of Sciences USSR, 1951. vol. LXXX1(2), pp. 179-182.

13. J.W. Rutter and B. Chalmers: Can. J. Physics, 1953. vol. 31(1), pp. 15-39.

14. W.A. Tiller, K.A. Jackson, J.W. Rutter, and B. Chalmers: Acta Metall., 1953. vol. 1, pp. 428-437.

15. W. Winegard and B. Chalmers: Trans. ASM, 1954. vol. 46, pp. 1214-1224.

16. V.G. Smith, W.A. Tiller, and J.W. Rutter: Can. J. Physics, 1955. vol. 33(12), pp. 723745.

17. R.E. Spear and G.R. Gardner: Modern Castings, 1963. vol. 43(5), pp. 209-215.

18. G.A. Chadwick: Metals and Materials, 1969. vol. 3(3), pp. 77-83.

19. B.L. Bramfitt: Metall. Trans., 1970. vol. 1(7), pp. 1987-1995.

20. I. Davies, J. Dennis, and A. Hellawell: Metall. Trans., 1970. vol. 1, pp. 275-280.

21. J. Marcantonio and L. Mondolfo: J. Inst. Metals, 1970. vol. 98, pp. 23-27.

22. J. Cisse, G. Bolling, and H. Kerr: J. Cryst. Growth, 1972. vol. 13/14, pp. 777-781.

23. S. Naess and O. Berg: Z. Metallkde., 1974. vol. 65, pp. 599-602.

24. D. Turnbull and B. Vonnegut: Ind. Eng. Chem., 1952. vol. 44(6), pp. 1292-1298.

25. F. Crossley and L. Mondolfo: JOM, 1951. vol. 191, pp. 1143-1151.

26. J.F. Wallace: Proceedings of Electric Furnace Conference, 1962, pp. 125-139.

27. L.A. Tarshis, J.L. Walker, and J.W. Rutter: Metall. Trans., 1971. vol. 2, pp. 25892597.

28. I. Maxwell and A. Hellawell: Acta Metall., 1975. vol. 23, pp. 229-237.

29. P. Desnain, Y. Fautrelle, J.-L. Meyer, J.-P. Riquet, and F. Durand: Acta Metall. Mater., 1990. vol. 38(8), pp. 1513-1523.

30. M. Johnsson and L. Bäckerud: Z. Metallkde., 1996. vol. 87(3), pp. 216-220.

31. J. Hunt: Mater. Sci. Engng., 1984. vol. 65, pp. 75-83.

32. M. Johnsson: Z. Metallkde., 1994. vol. 85, pp. 781-785.

33. M. Johnsson: Thermochimica Acta, 1995. vol. 256, pp. 107-121.

34. G. Chai, L. Bäckerud, and L. Arnberg: Mater. Sci. Technol., 1995. vol. 11, pp. 10991103.

35. M.H. Burden and J.D. Hunt: J. Cryst. Growth, 1974. vol. 22(2), pp. 99-108.

36. T.E. Quested, A.T. Dinsdale, and A.L. Greer: Acta Mater., 2005. vol. 53, pp. 13231334.

37. T.E. Quested and A.L. Greer: Acta Mater., 2005. vol. 53, pp. 4643-4653. 
38. T.E. Quested and A.L. Greer: Mater. Sci. Technol., 2005. vol. 21(9), pp. 985-994.

39. A.L. Greer, P. Cooper, M.W. Meredith, W. Schneider, P. Schumacher, J.A. Spittle, and A. Tronche: Adv. Engng. Mater., 2003. vol. 5(1-2), pp. 81-91.

40. A.L. Greer: Philos. T. Roy. Soc. A, 2003. vol. 361, pp. 479-495.

41. A.L. Greer, A.M. Bunn, A. Tronche, P.V. Evans, and D.J. Bristow: Acta Mater., 2000. vol. 48, pp. 2823-2835.

42. P. Tøndel, Grain Refinement of Hypoeutectic Al-Si Alloys, in Department of Metallurgy. 1994, The University of Trondheim: Trontheim, Norway.

43. M. Qian, P. Cao, M.A. Easton, S.D. McDonald, and D.H. StJohn: Acta Mater., 2010. vol. 58, pp. 3262-3270.

44. J. Spittle and S. Sadli: Mater. Sci. Technol., 1995. vol. 11, pp. 533-537.

45. M.A. Easton and D.H. StJohn: Metall. Mater. Trans. A, 2005. vol. 36A(7), pp. 19111920.

46. D.H. StJohn, M. Qian, M.A. Easton, P. Cao, and Z. Hildebrand: Metall. Mater. Trans. A, 2005. vol. 36A(7), pp. 1669-1679.

47. M.A. Easton, A. Schiffl, J.-Y. Yao, and H. Kaufmann: Scripta Mater., 2006. vol. 55(4), pp. 379-382.

48. A. Becerra and M. Pekguleryuz: J. Mater. Res., 2009. vol. 24(5), pp. 1722-1729.

49. T.V. Atamaneko, D.G. Eskin, L. Zhang, and L. Katgerman: Metall. Mater. Trans. A, 2010. vol. 41A(8), pp. 2056-2066.

50. M. Kearns and P. Cooper: Mater. Sci. Technol., 1997. vol. 13, pp. 650-654.

51. I. Toda-Caraballo, E.I. Galindo-Nava, and P.E.J. Rivera-Díaz-del-Castillo: Acta Mater., 2014. vol. 75, pp. 287-296.

52. Y.C. Lee, A.K. Dahle, and D.H. StJohn: Metall. Mater. Trans. A, 2000. vol. 31A(11), pp. 2895-2906.

53. Y.C. Lee, A.K. Dahle, D.H. StJohn, and J.E.C. Hutt: Mater. Sci. Engng. A, 1999. vol. 259, pp. 43-51.

54. R. Schmid-Fetzer and A. Kozlov: Acta Mater., 2011. vol. 59, pp. 6133-6144.

55. I. Maxwell and A. Hellawell: Acta Metall., 1975. vol. 23, pp. 901-909.

56. W. Kurz and D. Fisher: Fundamentals of Solidification, 4th edition. 1998: Trans Tech Publications, Switzerland.,

57. A. Tronche and A.L. Greer: Continuous Casting, 2000, DGM and Wiley-VCH, pp. 218-223.

58. M.A. Easton and D.H. StJohn, The Effect of Alloy Content on the Grain Refinement of Aluminium Alloys, in Light Metals 2001, J.L. Anjier, Editor. 2001, The Minerals, Metals and Materials Society, Warrendale, Pennsylvania. pp. 927-934.

59. D.H. StJohn, M.A. Easton, M. Qian, and J.A. Taylor: Metall. Mater. Trans. A, 2013. vol. 44(7), pp. 2935-2949.

60. F. Hodaj and F. Durand: Acta Mater., 1997. vol. 45(5), pp. 2121-2127.

61. M.A. Easton and D.H. StJohn: Mater. Sci. Technol., 2000. vol. 16(9), pp. 993-1000.

62. J. Gröbner, D. Mirković, and R. Schmid-Fetzer: Mater. Sci. Engng. A, 2005. vol. 395, pp. 10-21.

63. F. Wang, Z. Liu, D. Qiu, J.A. Taylor, M.A. Easton, and M.-X. Zhang: Acta Mater., 2013. vol. 61(1), pp. 360-370.

64. M. Kearns and P. Cooper: Light Metals 1997, 1997, TMS(The Minerals, Metals \& Materials Society), Warrendale, PA, pp. 655-661.

65. Y. Birol: Inter. J. Cast Metals Res., 2013. vol. 26(1), pp. 22-27.

66. J.E.C. Hutt, A.K. Dahle, Y.C. Lee, and D.H. StJohn: Light Metals 1999, 1999. vol., pp. 685-692. 
67. P. Schempp, C.E. Cross, A. Pittner, and M. Rethmeier: Metall. Mater. Trans. A, 2013. vol. 44(7), pp. 3198-3210.

68. D.H. StJohn, P. Cao, M. Qian, and M.A. Easton: Adv. Engng. Mater., 2007. vol. 9(9), pp. 739-746.

69. M.A. Easton and D.H. StJohn: Mater. Sci. Engng. A, 2008. vol. 486(1-2), pp. 8-13.

70. J. Dai, M.A. Easton, M.-X. Zhang, D. Qiu, X.-Y. Xiong, W. Liu, and G. Wu: Metall. Mater. Trans. A, 2014. vol. 45A(9), pp. 4665-4678.

71. A.V. Nagasekhar, C. Cáceres, and M.A. Easton: Mater. Sci. Forum, 2009. vol. 618619, pp. 479-482.

72. A. Ramirez, M. Qian, B. Davis, T. Wilks, and D.H. StJohn: Scripta Mater., 2008. vol. 59(1), pp. 19-22.

73. B. Chalmers: J. Aust. Inst. Metals, 1963. vol. 8(3), pp. 255-263.

74. J.E.C. Hutt and D.H. StJohn: Inter. J. Cast Metals Res., 1998. vol. 11(1), pp. 13-22.

75. D. Liang, Z. Liang, Q. Zhai, G. Wang, and D.H. StJohn: Materials Letters, 2014. vol. 130, pp. 48-50.

76. K. Nogita, Y. H, A. Prasad, S.D. McDonald, T. Nagira, N. Nakatsuka, K. Uesugi, and D.H. StJohn: Mater. Char., 2013. vol. 85(11), pp. 134-140.

77. M.A. Easton, D.H. StJohn, and A. Prasad, Grain refinement of aluminium alloys: recent developments in predicting the as-cast grain size of alloys refined by Al-Ti-B master alloys, in Light Metals 2014, J. Grandfield, Editor. 2014, TMS (The Minerals, Metals \& Materials Society). pp. 939-944.

78. D. Shu, B. Sun, J. Mi, and P.S. Grant: Acta Mater., 2011. vol. 59(5), pp. 2135-2144.

79. Q. Du and Y. Li: Acta Mater., 2014. vol. 71, pp. 380-389.

80. H.B. Aaron, D. Fainstein, and G.R. Kotler: J. Appl. Phys., 1970. vol. 41(11), pp. 4404-4410.

81. W.W. Mullins and R.F. Sekerka: J. Appl. Phys., 1963. vol. 34(2), pp. 323-329.

82. S.R. Coriell and R.L. Parker: J. Appl. Phys., 1965. vol. 36(2), pp. 632-637.

83. R. Trivedi and W. Kurz: Acta Mater., 1994. vol. 42(1), pp. 15-23.

84. D. Shu, B. Sun, J. Mi, and P.S. Grant: Acta Mater., 2011. vol. 59, pp. 2135-2144.

85. M. Rappaz and P. Thévoz: Acta Metall., 1987. vol. 35(12), pp. 2929-2933.

86. R. Wagner and R. Kampmann: Homogeneous second phase precipitation, in Materials science and technology: a comprehensive treatment, R.W. Cahn, Editor. 1991, John Wiley: Weinheim. pp.

87. K.A. Jackson, J.D. Hunt, D.R. Uhlmann, and T.P. Seward: Transactions of the Metallurgical Society of AIME, 1966. vol. 236, pp. 149-158.

88. A.E. Ohno: Solidification - The Separation Theory and its Practical Applications. Springer-Verlag, Heidelberg, Germany. 1987,

89. D.H. StJohn, M.A. Easton, and M. Qian: Solid State Phenom., 2008. vol. 141-143, pp. 355-360.

90. W.U. Mirihanage, L. Arnberg, and R.H. Mathiesen: IOP Conference Series: Materials Science and Engineering, 2012. vol. 33, pp. 012033.

91. E. Liotti, A. Lui, S. Kumar, Z. Guo, T. Connolley, I.P. Dolbnya, M. Hart, L. Arnberg, R.H. Mathiesen, and P.S. Grant: Acta Mater., 2014. vol. 70(1), pp. 228-239.

92. D. Shu, B. Sun, J. Mi, and P.S. Grant: Metall. Mater. Trans. A, 2012. vol. 43(10), pp. 3755-3766.

93. G. Wang, M.S. Dargusch, M. Qian, D.G. Eskin, and D.H. StJohn: J. Cryst. Growth, 2014. vol. 408, pp. 119-124. 
94. E.Q. Wang, G. Wang, M.S. Dargusch, M. Qian, D.G. Eskin, and D.H. StJohn, Grain Refinement of an Al-2 wt\%Cu Alloy by Al3Ti1B Master Alloy and Ultrasonic Treatment, in ICASP-4. 2014: Old Windsor, UK. pp. submitted for publication.

95. J. Lipton, W. Kurz, and R. Trivedi: Acta Metall., 1987. vol. 35(4), pp. 957-964.

96. A. Prasad, Microsegregation studies of Rapidly Solidified binary Al-Cu alloys, in Chemical and Materials Engineering. 2006, University of Alberta: Edmonton, Alberta.

97. M. Rappaz and P. Thevoz: Acta Mater., 1987. vol. 35, pp. 2929-2933.

98. J.A. Dantzig and M. Rappaz: Solidification. 2009, Lausanne, Swizerland: EPFL press, 305.

99. D.G. McCartney: Inter. Mater. Rev., 1989. vol. 34, pp. 247-260. 


\section{Table of Symbols}

a Constant related to the maximum number of particles that can be successfully activated as nucleants

$b \quad$ Slope of the best fit line through the grain size data plotted against $1 / Q$

$C_{o} \quad$ Alloy composition [wt. \%]

$C_{l} \quad$ Composition of the liquid in front of the solid-liquid interface [wt. \%]

$C_{l}^{*} \quad$ Composition of the liquid at the solid-liquid interface

$C_{p} \quad$ Specific heat $\left[\mathrm{J} \mathrm{m}^{-3} \mathrm{~K}^{-1}\right]$

$C_{s}^{*} \quad$ Composition of the solid at the solid-liquid interface

CS Constitutional Supercooling. The terms Constitutional Supercooling (CS) [K] 14, 73, 98 and Constitutional Undercooling (CU) ${ }^{56}$ have the same meaning and are both used in the solidification literature.

$d_{g s} \quad$ Grain size $[\mu \mathrm{m}]$

d Nucleant particle diameter $[\mu \mathrm{m}]$

D Rate of solute diffusion in the liquid $\left[\mathrm{m}^{2} \mathrm{~s}^{-1}\right]$

fs $\quad$ Fraction solid $[-]$

$I v\left(P_{c}\right)$ Solution to solute diffusion from a parabolic tip

$I v\left(P_{t}\right)$ Solution to heat diffusion from a parabolic tip

$k \quad$ Partition coefficient $C_{s} / C_{l}$

$l_{D} \quad$ Characteristic diffusion length/distance $[\mu \mathrm{m}]$

$L \quad$ Latent heat of fusion $\left[\mathrm{J} \mathrm{m}^{-3}\right]$

$m \quad$ Slope of the liquidus

$P \quad$ Supercooling parameter and equals $m C_{o}(k-1) / k$

$P_{c} \quad$ Peclet number for solute diffusion

$P_{t} \quad$ Peclet number for heat diffusion

$Q \quad$ Growth restriction factor and equals $m C_{o}(k-1)$ 
$r^{*} \quad$ Length of the diffusion field $[\mathrm{Du}, \mathrm{Li}] \quad[\mu \mathrm{m}]$

$r^{o} \quad$ Grain envelope radius $[\mathrm{Du}, \mathrm{Li}] \quad[\mu \mathrm{m}]$

$R_{d} \quad$ Radius of the dendrite tip $\quad[\mu \mathrm{m}]$

$S_{d} \quad$ Average particle spacing for a particle of diameter $d \quad[\mu \mathrm{m}]$

$\begin{array}{lll}t & \text { Time }\end{array}$

$\Delta T \quad$ Undercooling below the equilibrium liquidus temperature $\quad[\mathrm{K}]$

$\Delta T_{c} \quad$ liquidus temperature of the alloy minus the liquidus temperature

of the new liquid composition after a fraction solid, $f_{s} \quad[\mathrm{~K}]$

$\Delta T_{c s} \quad$ Amount of Constitutional Supercooling $\quad[\mathrm{K}]$

$\Delta T_{f r} \quad$ Freezing range $\quad[\mathrm{K}]$

$\Delta T_{n} \quad$ Undercooling for nucleation $\quad[\mathrm{K}]$

$\Delta T_{r} \quad$ Curvature undercooling $\quad[\mathrm{K}]$

$\begin{array}{lll}\Delta T_{t} & \text { Thermal undercooling } & {[\mathrm{K}]}\end{array}$

$T_{n} \quad$ Temperature at which nucleation will occur $\quad[\mathrm{K}]$

$\begin{array}{lll}T_{A} & \text { Actual temperature of the melt } & {[\mathrm{K}]}\end{array}$

$\begin{array}{lll}T_{E} \quad \text { Equilibrium liquidus temperature } & {[\mathrm{K}]}\end{array}$

$T_{M P} \quad$ Equilibrium melting temperature of pure metal $\quad[\mathrm{K}]$

$v \quad$ Growth velocity $\quad\left[\mathrm{ms}^{-1}\right]$

$w^{*} \quad$ Length of the diffusion field [Shu et al] $\quad[\mu \mathrm{m}]$

$x \quad$ Distance in the $x$-direction from the center of a grain $\quad[\mu \mathrm{m}]$

$x$, Distance in the $x$-direction from the solid-liquid interface $\quad[\mu \mathrm{m}]$

$x_{C S} \quad$ Distance a grain needs to grow to create CS sufficient to nucleate a grain $[\mu \mathrm{m}]$

$x_{d l} \quad$ Generic distance of the diffusion field from the S-L interface to the point where

$\mathrm{CS}$ is sufficient to nucleate a grain, i.e. when $\Delta T_{c s}$ first equals $\Delta T_{n-\min } \quad[\mu \mathrm{m}][\mathrm{Ref}]$ 
$x^{\prime} d l \quad$ Distance of the diffusion field from the S-L interface to the point where

$\mathrm{CS}$ is sufficient to nucleate a grain, i.e. when $\Delta T_{c s}$ first equals $\Delta T_{n-m i n}$

$[\mu \mathrm{m}][\mathrm{Ref}]$

$x_{n f z} \quad$ Length of the nucleation-free zone $\quad[\mu \mathrm{m}]$

$x_{S d} \quad$ Distance between $x_{n f z}$ and the next most potent particle in the melt $\quad[\mu \mathrm{m}]$

$z \Delta T_{n} \quad$ Incremental amount of undercooling required to re-establish $\Delta T_{n} \quad[\mathrm{~K}]$

$\underline{\text { Greek symbols }}$

$\alpha \quad$ Rate of thermal diffusion $\quad\left[\mathrm{m}^{2} \mathrm{~s}^{-1}\right]$

$\Gamma \quad$ Gibbs-Thomson coefficient $\quad[\mathrm{mK}]$

$\delta_{c} \quad$ Size of the solute diffusion boundary layer equal to $D / v \quad[\mu \mathrm{m}]$

$\Omega \quad$ Supersaturation term equals $\left(\frac{C_{l}^{*}-C_{0}}{C_{l}^{*}-C_{s}^{*}}\right)$ 


\section{Tables}

Table I. Comparison of the relative values of $Q$ and $P$ for some common elemental additions at the same values of $C_{O}$ to Al-alloys obtained from ${ }^{30,99}$.

\begin{tabular}{llllll}
\hline Element & $\mathrm{K}$ & $\mathrm{m}(\mathrm{K} / \mathrm{wt} \%)$ & $\begin{array}{l}\text { max. } \\
\text { solubility }\end{array}$ & $\mathrm{m}(\mathrm{k}-1)$ for $Q$ & $\mathrm{~m}(\mathrm{k}-1) / \mathrm{k}$ for $P$ \\
\hline $\mathrm{Ti}$ & $7-8$ & 33.3 & 0.15 & $\sim 220$ & $\sim 30$ \\
$\mathrm{Zr}$ & 2.5 & 4.5 & 0.11 & 6.8 & 2.7 \\
$\mathrm{Si}$ & 0.11 & -6.6 & $\sim 12.6$ & 5.9 & 54 \\
$\mathrm{Cr}$ & 2 & 3.5 & $\sim 0.4$ & 3.5 & 1.8 \\
$\mathrm{Ni}$ & 0.007 & -3.3 & $\sim 6$ & 3.3 & 471 \\
$\mathrm{Mg}$ & 0.51 & -6.2 & $\sim 3.4$ & 3 & 5.9 \\
$\mathrm{Fe}$ & 0.02 & -3 & $\sim 1.8$ & 2.9 & 145 \\
$\mathrm{Cu}$ & 0.17 & -3.4 & 33.2 & 2.8 & 16.5 \\
$\mathrm{Mn}$ & 0.94 & -1.6 & 1.9 & 0.1 & 0.1 \\
\hline
\end{tabular}

Table I. Phase diagram and thermo-physical properties for the Al-7Si alloy used in the calculations.

\begin{tabular}{lll}
\hline Item & Value & Units \\
\hline Solute diffusion, $D$ & $1.98 \times 10^{-9}$ & $\mathrm{~m}^{2} / \mathrm{s}$ \\
Partition coefficient, $k$ & 0.17 & - \\
Liquid slope, $m$ & -6.6 & $\mathrm{~K} /[\%]$ \\
Gibbs-Thomson coefficient, $\Gamma$ & $9 \times 10^{-8}$ & $\mathrm{mK}$ \\
Latent heat of fusion, $L$ & $1.31 \times 10^{9}$ & $\mathrm{~J} / \mathrm{m}^{3}$ \\
Specific heat, $C_{p}$ & $2.67 \times 10^{6}$ & $\mathrm{~J} / \mathrm{m}^{3} / \mathrm{K}$ \\
Thermal diffusion, $\alpha$ & $8.7 \times 10^{-5}$ & $\mathrm{~m}^{2} / \mathrm{s}$ \\
Freezing range, $\Delta T_{f r}$ & 36 & $\mathrm{~K}$ \\
\hline
\end{tabular}




\section{Figures}

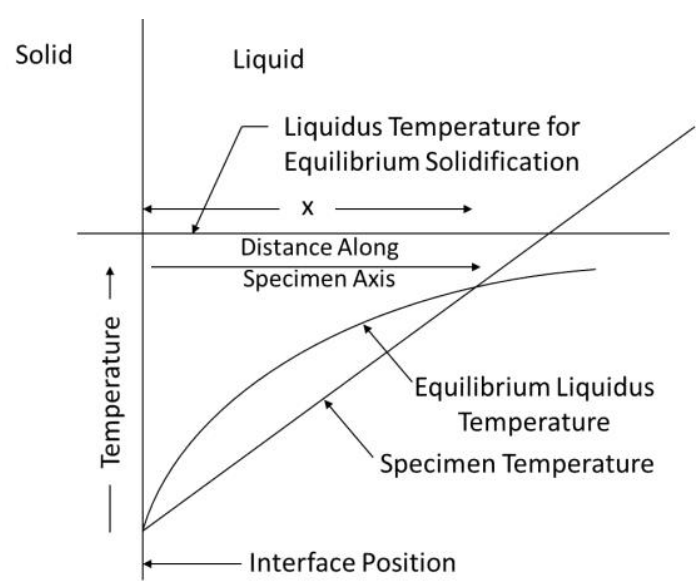

Fig. 1 A schematic description of the CS theory developed by Rutter and Chalmers ${ }^{13}$, reproduced.

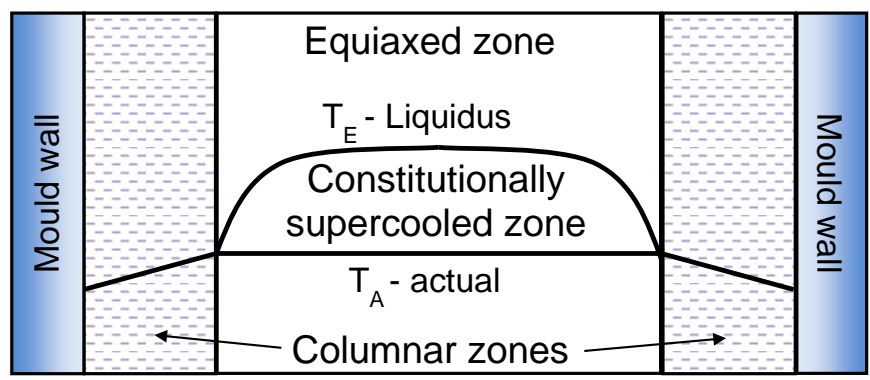

Fig. 2. Representation of the conditions for the establishment of an equiaxed zone as described by Winegard and Chalmers ${ }^{15}$ where $T_{E}$ is the equilibrium liquidus temperature and $T_{A}$ is the actual temperature of the melt.

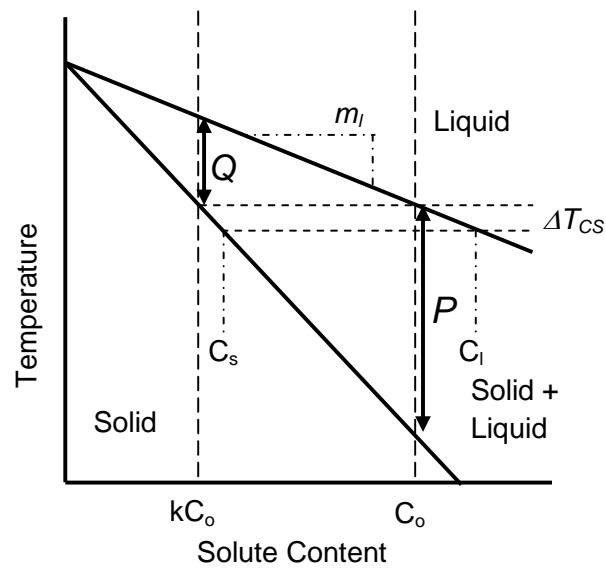

Fig. 3. The implications of $P$ and $Q$ in a binary eutectic system. Reproduced from Ref. ${ }^{36}$. 


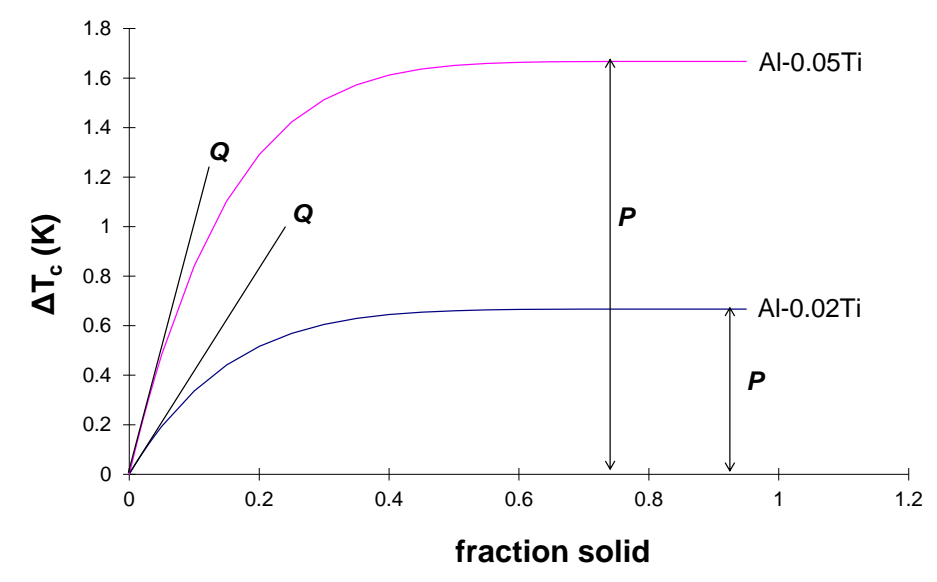

Fig. 4. Illustration of the value of $Q$ as the initial rate of CS development and $P$ as the maximum value in the Al-Ti system ${ }^{9}$.
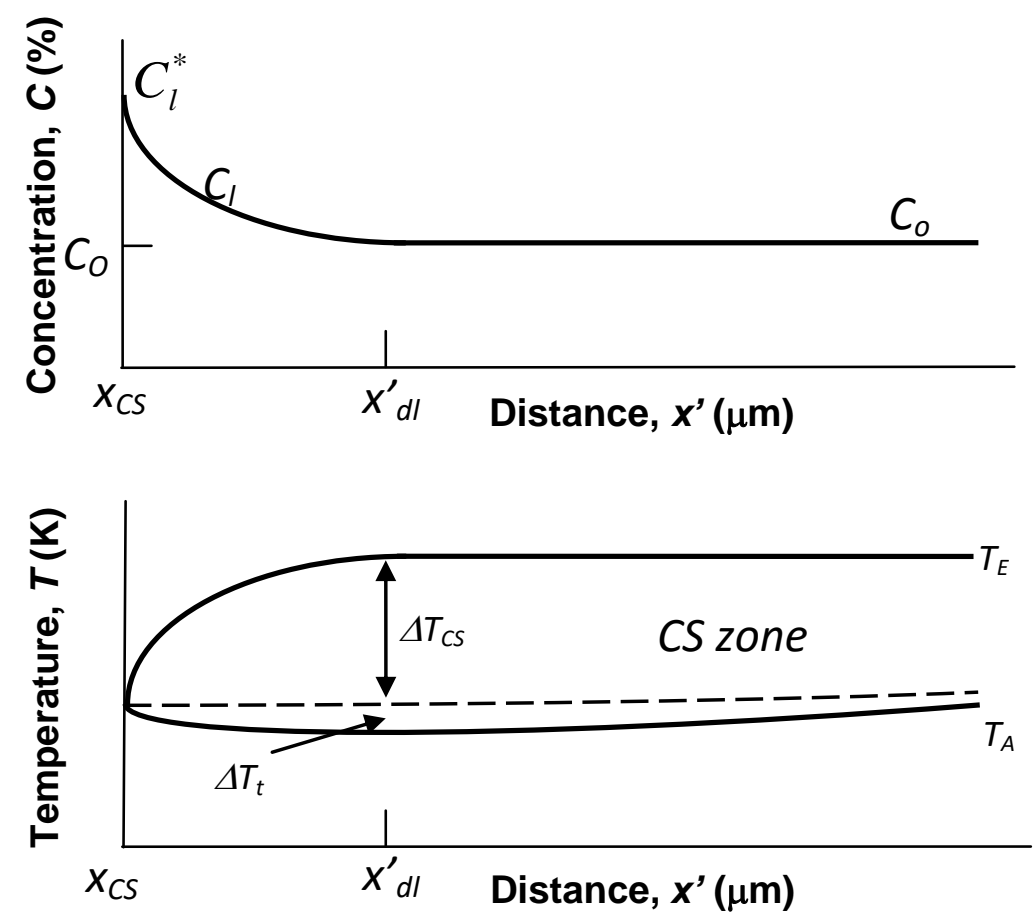

Fig. 5: Schematic representation of the development of the CS zone in front of a growing equiaxed grain: (a) is the composition profile of the solute rejected in front of the growing $\mathrm{S}$ L interface where $x^{\prime}{ }_{d l}$ is the length of the diffusion field ahead of the growing interface, and (b) the conversion of composition to their equilibrium liquidus temperatures, $T_{E}$, and the actual temperature, $T_{A}$. The CS zone is formed where $T_{E}$ is greater than $T_{A}$. 


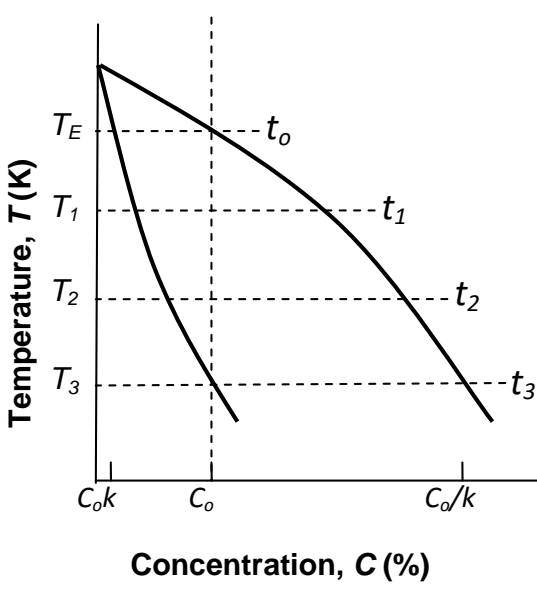

(a)

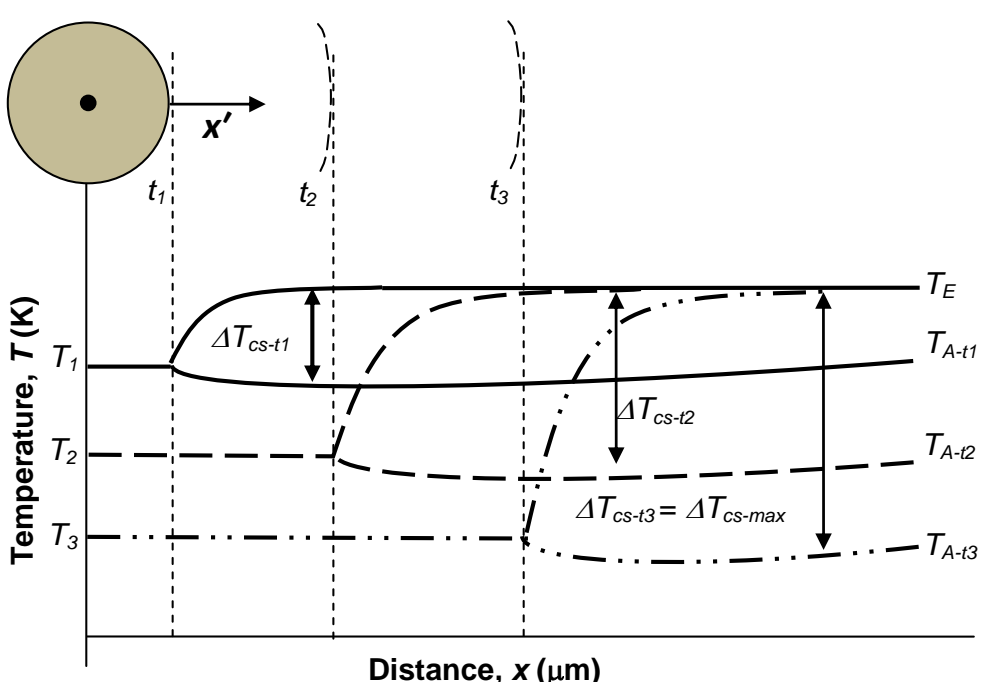

(b)

Fig. 6. The solidification pathway during the initial transient for an alloy of composition $C_{o}$. (a) shows the temperature-composition evolution of the S-L interface during the initial transient until steady-state growth begins at $T_{3}$. (b) Represents the conversion of the concentration profile in Figure 5 into profiles of the equilibrium liquidus temperature, $T_{E}$, for each time step $t_{1}$ to $t_{3} . T_{A}$, the actual temperature in the melt, decreases from $T_{A-t}$ to $T_{A-t 3}$. The slight curvature of $T_{A}$ in front of the S-L interface is due to the assumption of equiaxed growth where the growing grains are hotter than the surrounding liquid due to the transfer of latent heat into the liquid. The amount of CS generated is the difference between $T_{E}$ and $T_{A}$ for each time step. Note that the length of the CS zone is defined by $x$ ' where the origin is at the S-L interface. 


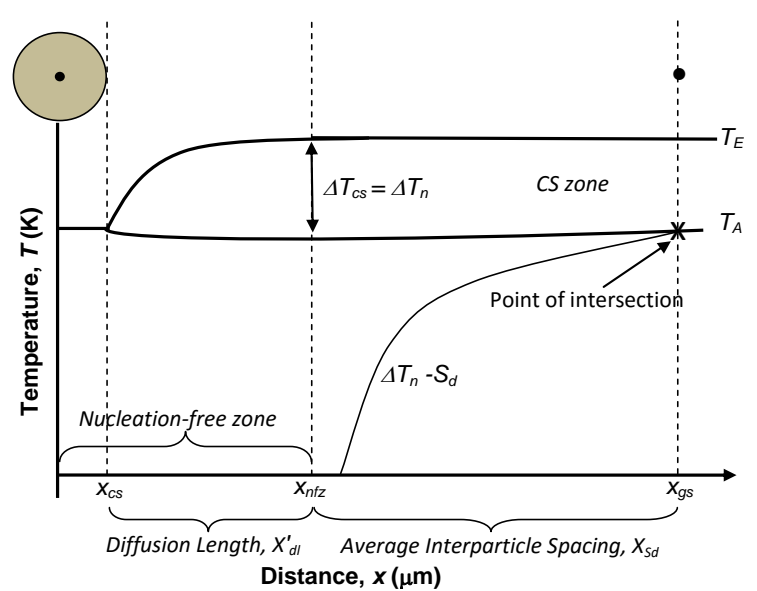

(a)

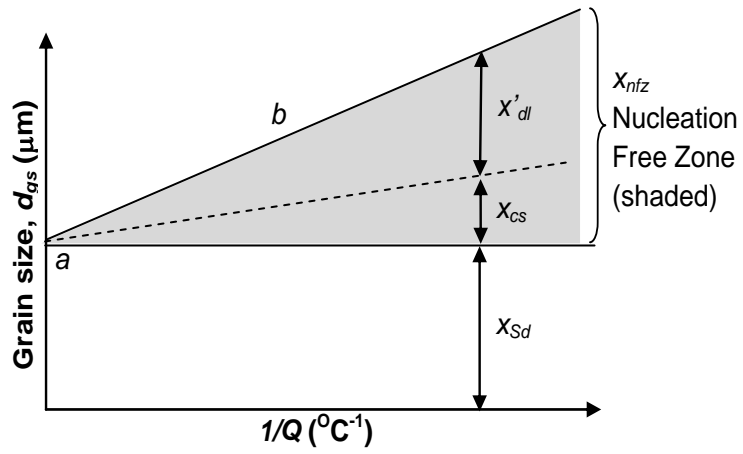

(b)

Fig. 7. (a) Schematic representation showing the intersection between $T_{A}$ and the $\Delta T_{n}-S_{d}$ curve indicating the location of the nucleation event, and the three regions that together establish the grain size of the microstructure: $x_{C S}, x^{\prime}{ }_{d l}$ and $x_{S d}$. The first two regions $x_{c s}$ and $x^{\prime}{ }_{d l}$ together represent a nucleation-free zone where nucleation is not possible for the particle distribution described by $\Delta T_{n}-S_{d}$. (b) A simple representation illustrating that for each value of $Q$ the grain size is the result of three components: $x_{S d}$ is the average distance to the activated particles and $b$ is equal to the gradient of $x_{C S}$ plus $x^{\prime}{ }_{d l}$ over a unit of $1 / Q . x_{S d}$ is a constant when the particle number density is constant as illustrated in (b).

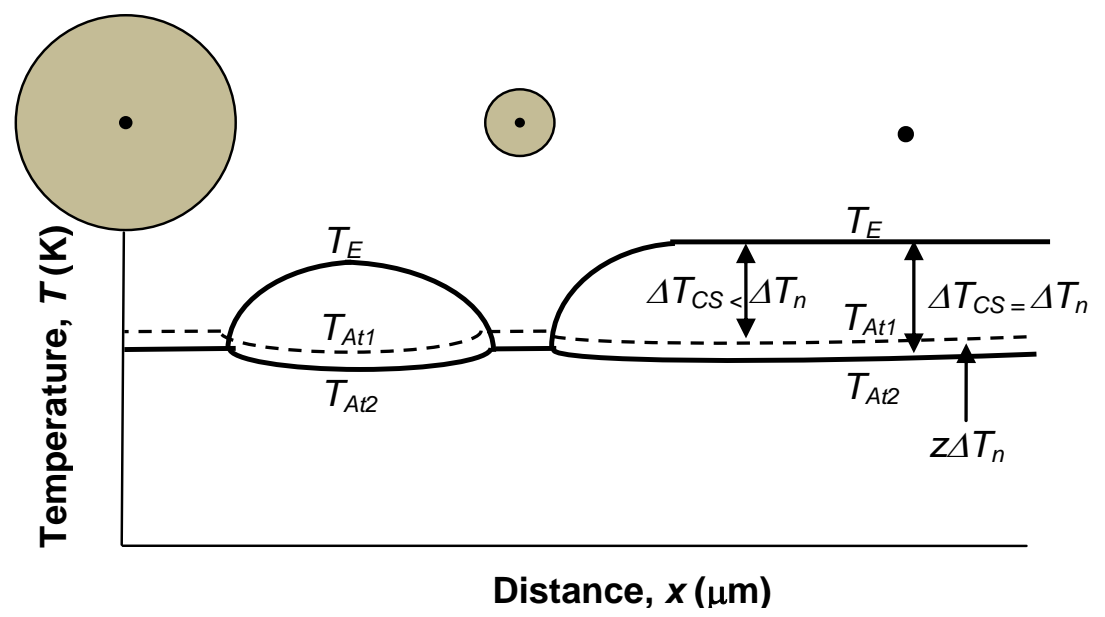

Figure 8. Representation of the repeating cycles of growth, nucleation and growth generating CS where the undercooling required to re-establish $\Delta T_{C S}$ equal to $\Delta T_{n}$ is the difference between the dashed lines denoted by $z \Delta T_{n}$ as the temperature gradient of $T_{A}$ moves in the $x$ direction. The black dots represent activated nucleant particles. The dashed line illustrates the temperature gradient before moving to a lower temperature as the melt cools. 
$5 s$

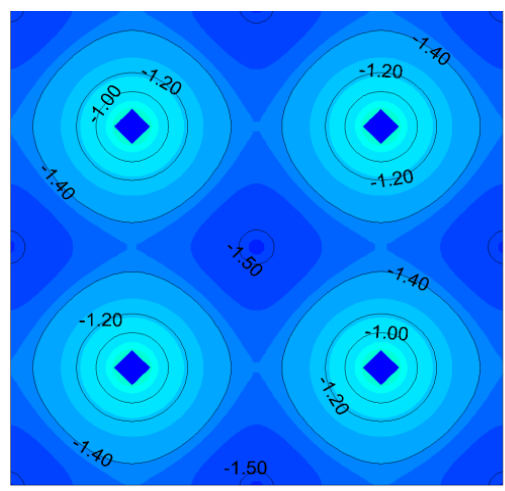

$\Delta T_{C S} \quad-1.5^{\circ} \mathrm{C}$
$10 \mathrm{~s}$

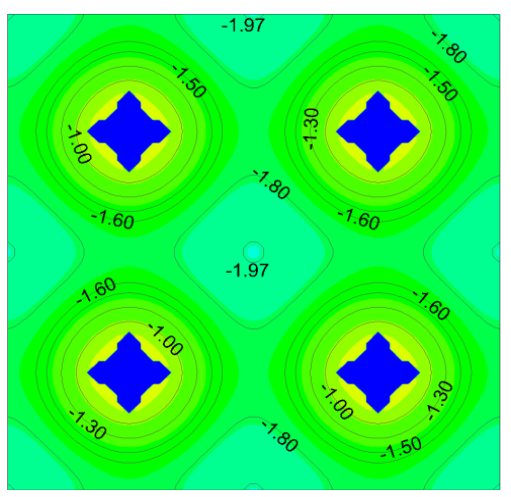

$-1.97^{\circ} \mathrm{C}$
$15 s$

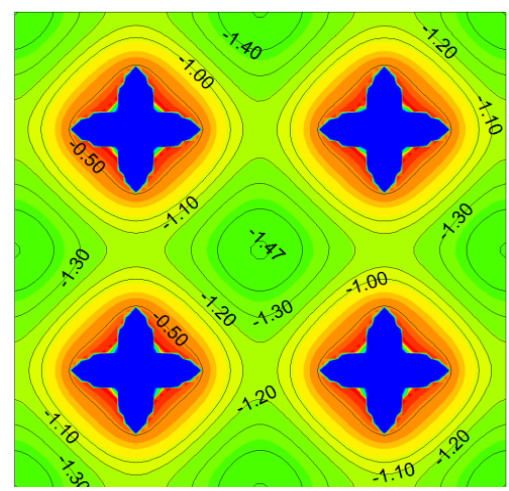

$-1.47^{\circ} \mathrm{C} \quad \stackrel{1 \times 10^{-4} \mathrm{~m}}{ }$

Figure 9. Outputs of the numerical simulation of the growth of four dendritic equiaxed grains. The figure shows the development of the diffusion field (represented by compositional contour lines) surrounding the growing dendritic grains and the effect of solutal accumulation between adjacent grains ${ }^{11}$.

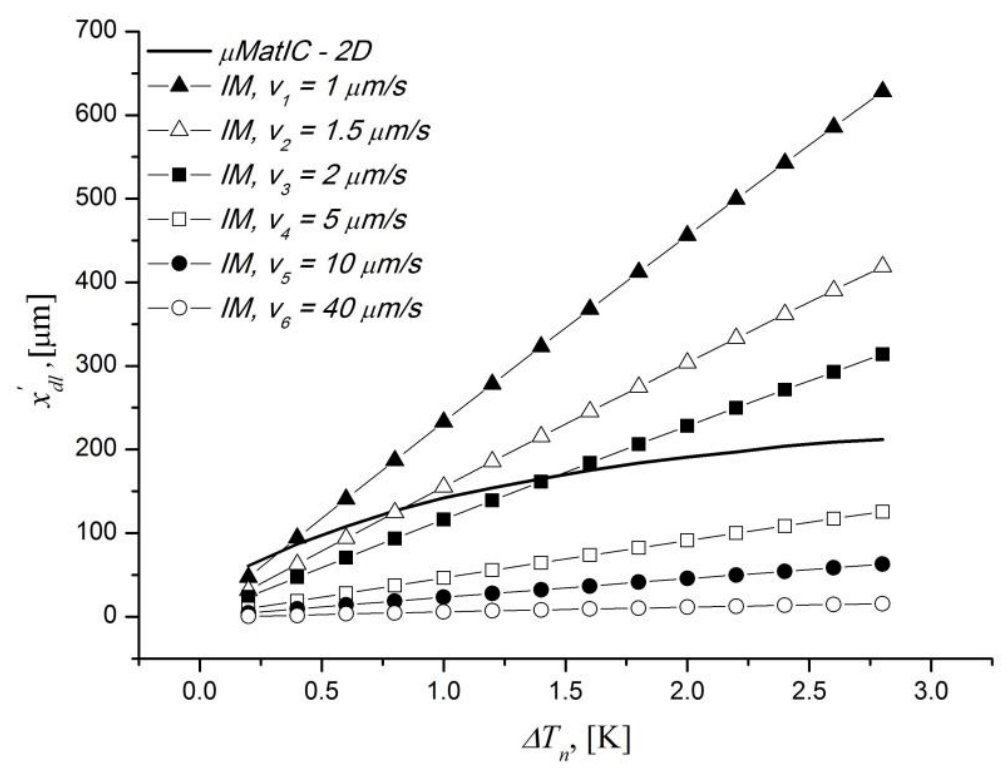

Fig. 10. $x_{d l}$ from the interface as a function of nucleation undercooling for the Interdependence model and the $\mu$ MatIC model. The user-defined growth rates used are $v_{1}=1 \mu \mathrm{m} / \mathrm{s}, v_{2}=1.5 \mu \mathrm{m} / \mathrm{s}, v_{3}=2$ $\mu \mathrm{m} / \mathrm{s}, v_{4}=5 \mu \mathrm{m} / \mathrm{s}, v_{5}=10 \mu \mathrm{m} / \mathrm{s}$ and $v_{6}=40 \mu \mathrm{m} / \mathrm{s}$. 


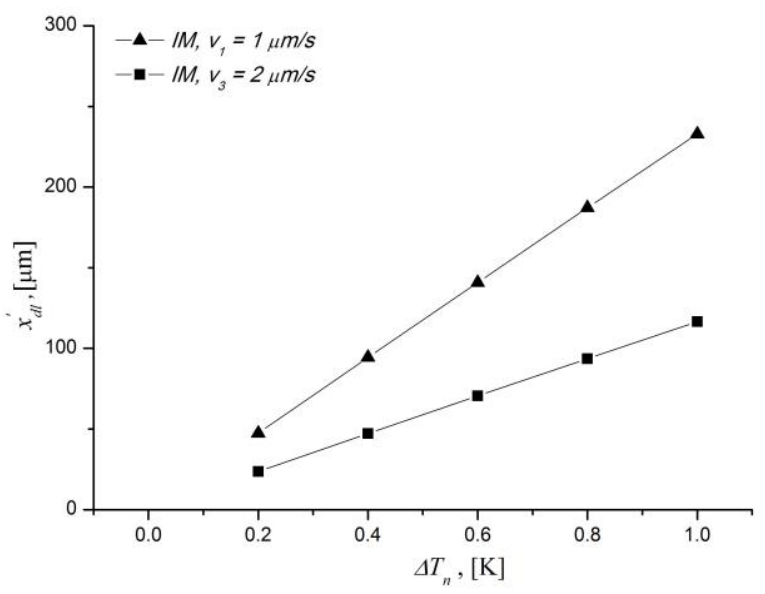

(a)

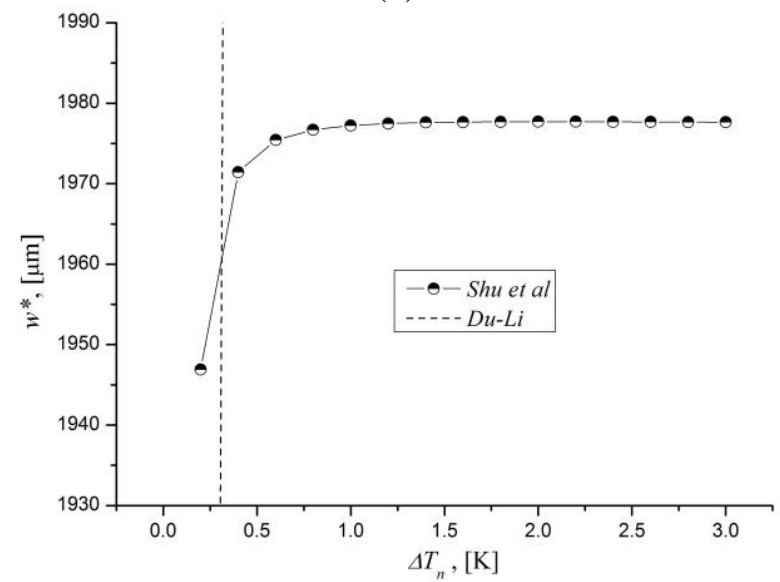

(b)

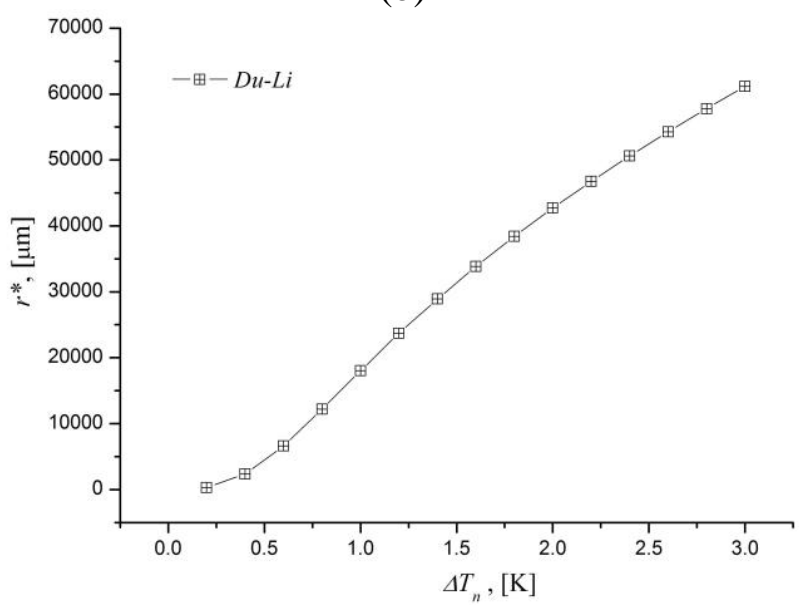

(c)

Fig. 11. a) $x_{d l}$ calculated from the Interdependence model for $v=2 \mu \mathrm{m} / \mathrm{s}$ (filled black squares), the Shu et al model and the Du-Li model. The Shu et al and Du-Li models give much larger values relative to the Interdependence model (notice the different $\mathrm{Y}$-axis scale). At small undercoolings, the Shu et al model gives larger values than the Du-Li model, but this reverses rapidly as undercooling increases. (b) shows the actual curved shape from the Shu et al model result that is dwarfed by the Du-Li results presented in (a). 


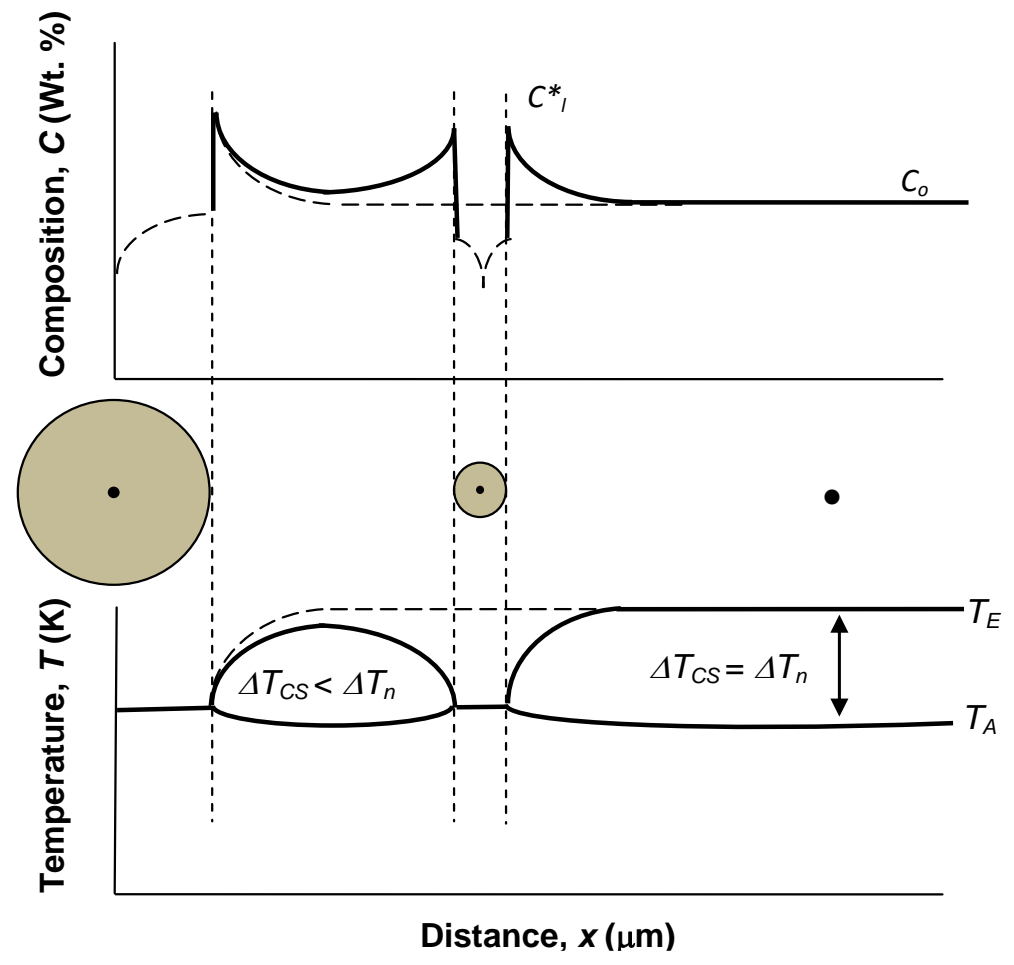

Figure 12. Schematic showing the composition and temperature profiles between, and in front of, the newly nucleated grains. The effect of overlapping diffusion fields between two growing grains is illustrated where the amount of CS reduces such that additional nucleation between the grains is not possible (i.e. $\Delta T_{C S}<\Delta T_{n}$ ). 


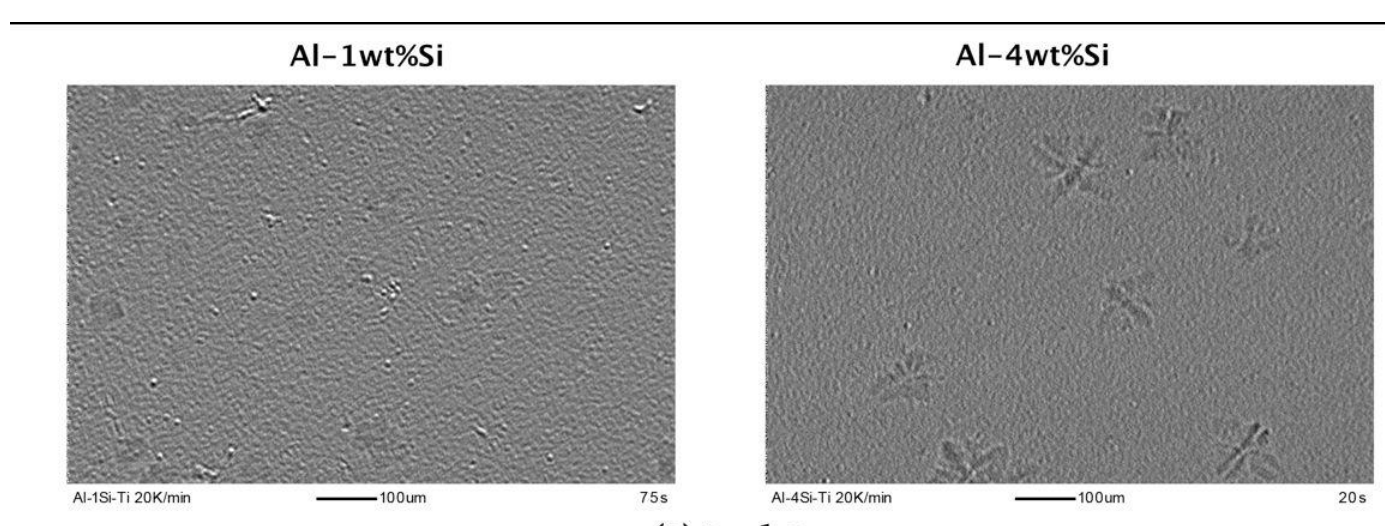

(a) $\mathrm{t}=1 \mathrm{~s}$
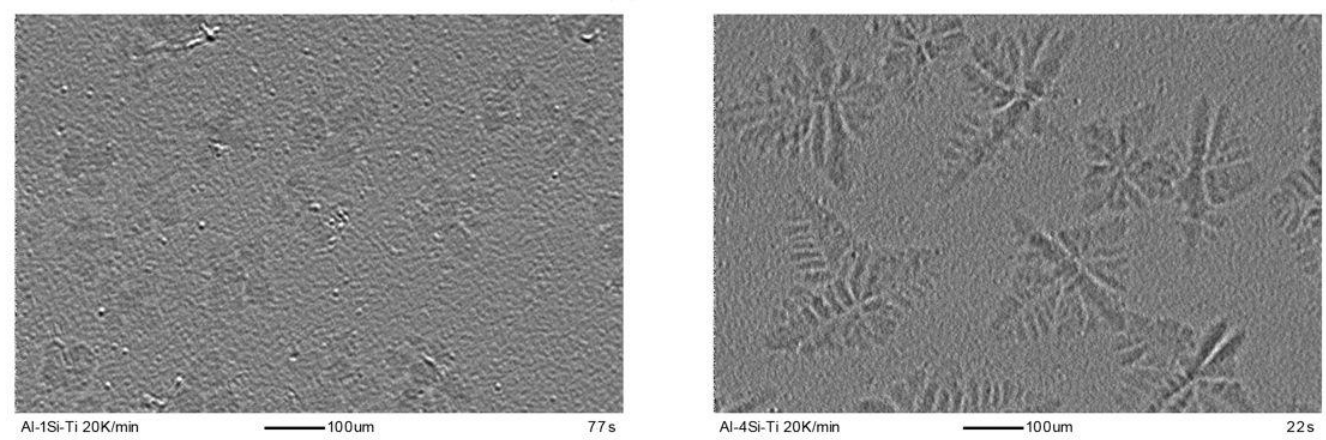

(b) $t=3 \mathrm{~s}$
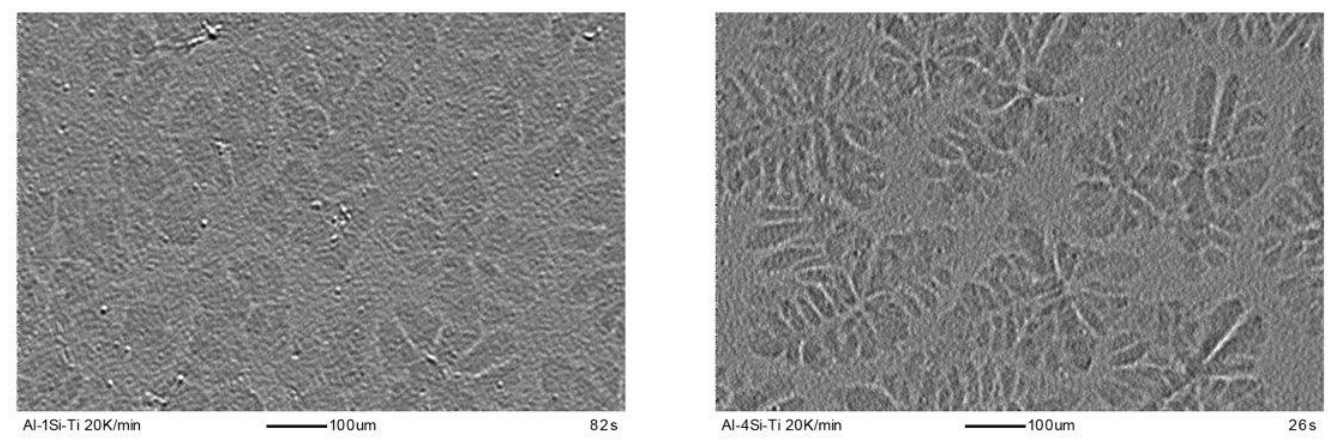

(c) $\mathrm{t}=7 \mathrm{~s}$

Fig. 13. Selected X-ray stills of solidification for the Al-1Si alloy, left, and the Al-4Si alloy, right. Time measurements are relative to the first observation of nucleation. The video sequences of solidification for each alloy can be found online associated with ${ }^{76}$. 


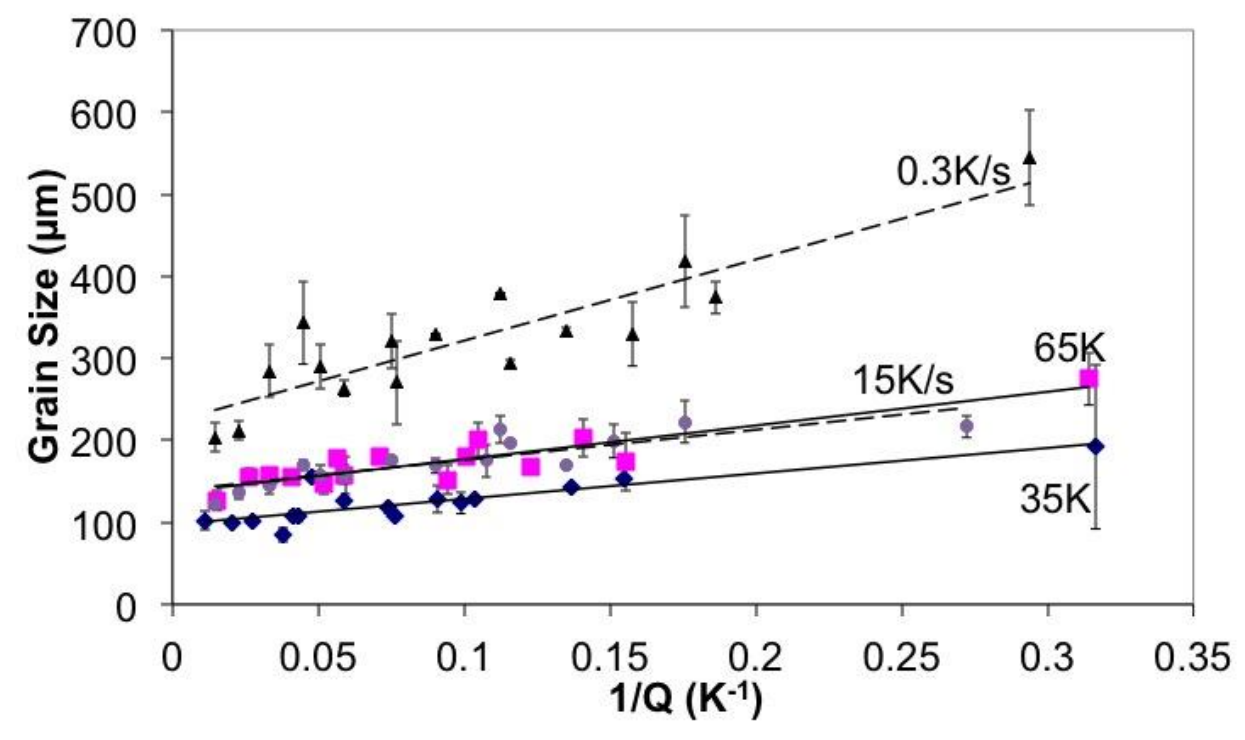

Fig. 14. A comparison of the effect of increasing cooling rate in a preheated graphite mould and reducing superheat in a permanent mould. It should be noted that the cooling rate in the centre of the permanent mould casting is also approximately $15 \mathrm{~K} / \mathrm{s}$. All alloys contain $0.005 \% \mathrm{TiB}_{2}$ as $\mathrm{Al}-3 \mathrm{Ti}-1 \mathrm{~B}{ }^{89}$. 


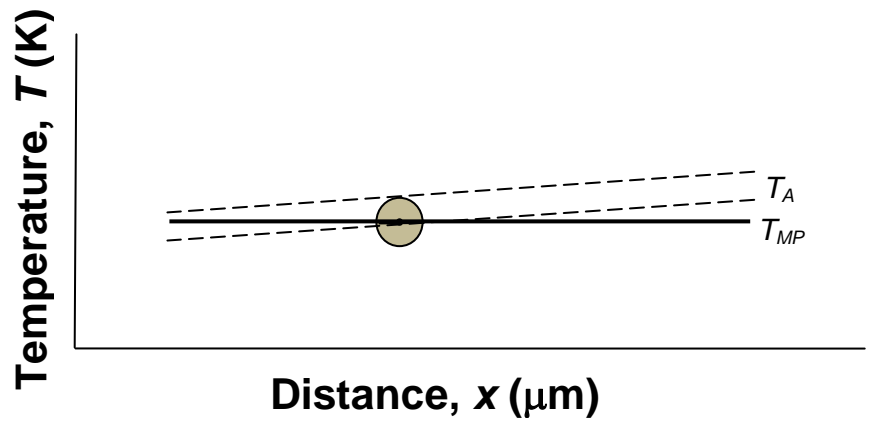

(a)

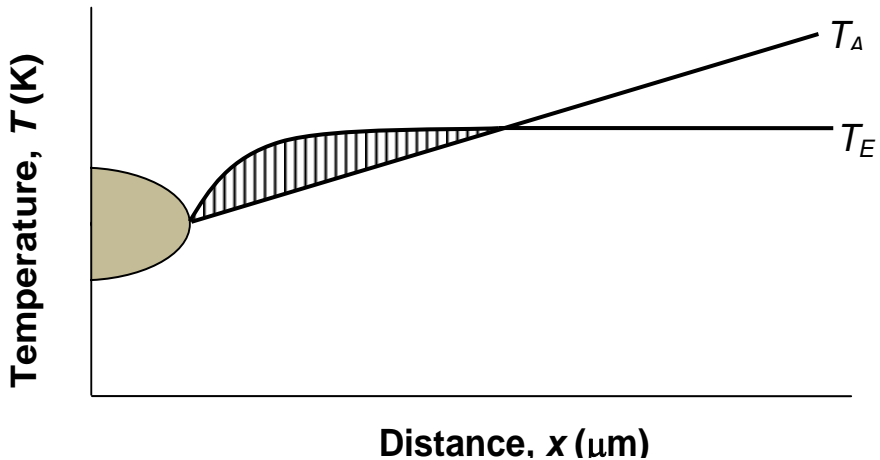

(b)

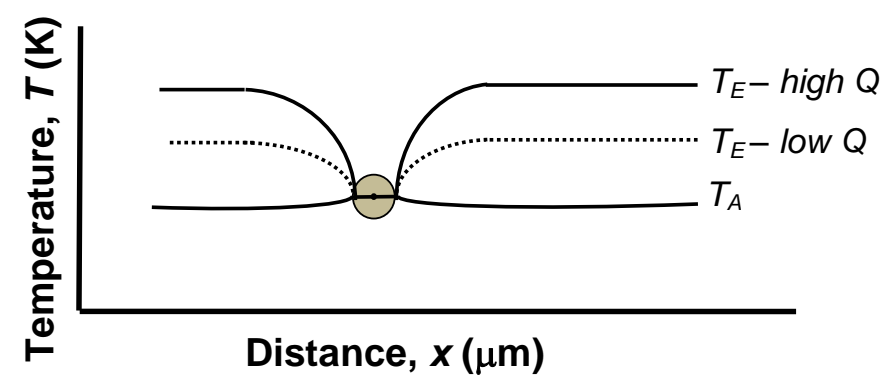

(c)

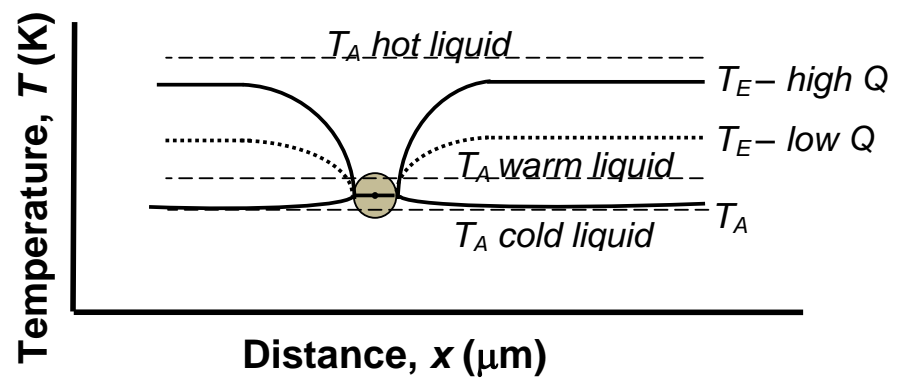

(d)

Figure 15. Schematic representations of the role of CS in protecting growing grains from remelting: (a) represents the situation of a pure metal grain growing in a pure melt; (b) directional solidification of an alloy where the CS zone provides some protection; (c) an equiaxed grain surrounded by CS providing good protection and the larger the $Q$ value the faster this protection is generated; and (d) is (c) but illustrating the effect of convection on $T_{A}$ in relation to $T_{E}$. $T_{A}$ : actual temperature gradient in the liquid; $T_{E}$ : the equilibrium liquidus temperature; $T_{M P}$ : melting point. 


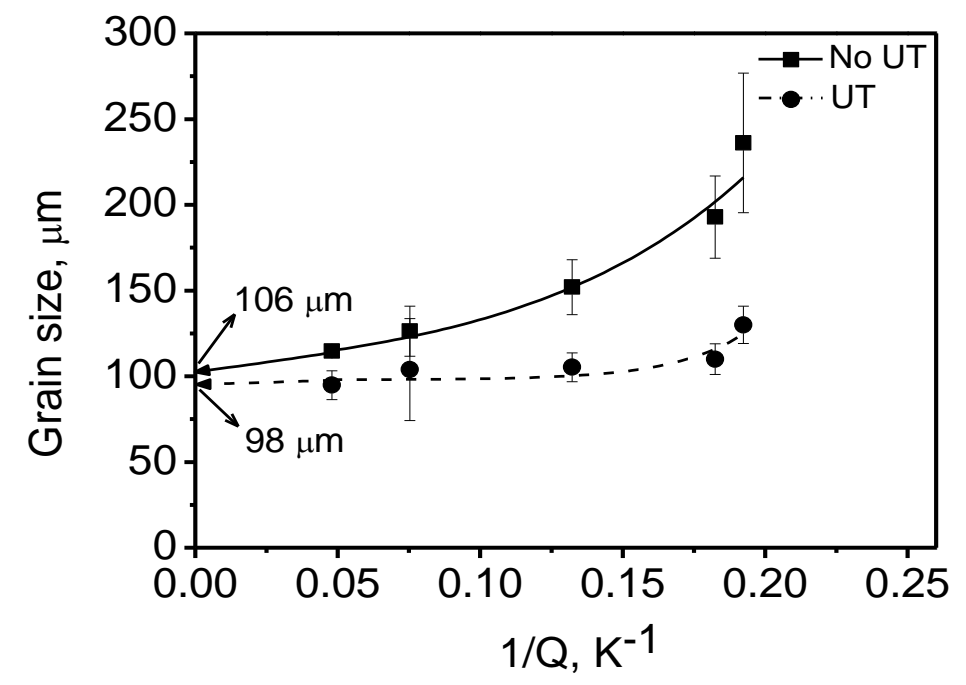

Fig. 16 The relationship between the grain size and the inverse of the growth restriction factor $Q$. 